\title{
Large-scale music compositions and novel technology innovations - Summarizing the process of Voices of Umeå, an artistic research project
}

\author{
Anders Lind
}

\begin{abstract}
Voices of Umeå was a three-year interdisciplinary artistic research project initiated in 2012 by the author. The main aim with the project was to explore new artistic possibilities for composition and performance practices within the field of contemporary art music. More specifically, artistic possibilities, which arises when non-professional performers regardless musical backgrounds enables to participate in the composition and performance processes. The idea was to develop and explore new pedagogical methods to involve non-professional performers by using new technology and combining knowledge from the fields of artistic and educational practices. Different aspects of participatory art were embraced in the artistic processes aiming towards three compositions, including two concerts and one exhibition. An action research model in three steps -planning, action and analysis of results inspired the methodology, where the analysis and experiences of each cycle within the project were affecting the further cycles of the project.

This article reports from selected parts of the process of the project and contributes with new knowledge to the fields of animated music notation and participatory art.
\end{abstract}

\section{Keywords}

Animated Music Notation, Participatory art, Non-Professional Performers, Interactive Music Instruments, Music Composition, Music Performance, Technology Innovations, Pedagogical Innovations, Human Voice, Action Research, Artistic Research.

\section{Introduction - Background and aims from two perspectives}

Composers working within the field of contemporary art music are in general used to compose music directly for high-skilled professional musicians. Having professional musicians as performers gives you the opportunity to explore the whole register of artistic possibilities of the traditional instruments. Since musicians dedicated to performing music within the field of contemporary art music are specialists on interpreting the western traditional notation system, as a composer you can communicate the musical ideas exactly as intended to the performer. However, as a composer you still have to be aware of the impact the choice of performers and their specific musical backgrounds will have to the artistic result. What would for instance happen to the artistic result if non-professional performers 
regardless musical background would be able to participate in a composition written within the field of contemporary art music?

As a composer I'm primarily interested in sounds and how they could be organized to achieve a novel composition. More specific, sounds organized in multiple individual parts to create interesting advanced musical textures. If the sounds were computer generated, performed by a professional musician or achieved by a school child, would in my opinion not necessary be crucial for the unique quality of the artistic expression. Indeed, having professional musicians performing in an orchestra gives you much more possibilities, due to their knowledge and background to accomplish your intended musical ideas. However, I do believe that having a crowd of non-professionals performing individual simple to execute sounds in multiple parts also could result in a unique artistic expression. The issue is how to organize the performance of a composition written in multiple parts if the performers not are familiar to the traditional notation system and to be led by a traditional conductor?. Indeed, experimenting with graphic notation could enable non-professionals to perform musical textures in multiple parts ${ }^{1}$, but still the artistic result is hard to predict since it's often based on improvisations and mainly open for individual interpretations.

In the artistic research project Voices of Umeå (VoU) I was interested in composing fixed compositions, where a crowd of non-professional performers also could be synchronized with electronically processed sounds. Furthermore, I wanted to work within the concept of participatory art, which fitted well into my intentions to work with crowds for the compositions. The choice of using the human voice and electronically processed sounds of the human voice as the only musical sound sources was because of its wide artistic possibilities and the fact that everybody with a sounding voice could be a potential participator in the project (Lind, 2015).

The artistic vision of the project was clear, but the overall question was how to get there. The complexity of the intended performances for the project demanded non-traditional methods to be able to reach the artistic visions within the project. Situated at a department with a focus on the field of education made me inspired to include a pedagogical perspective to achieve the artistic aims of the project. The ambition was to use an interdisciplinary approach to seek for innovatory solutions of the problems. The idea was: -To achieve the artistic aims of the project a pedagogical method and tool needed to be developed and explored, and in the contrary: To achieve the pedagogical aims of the project an artistic process needed to be put into action and to be analyzed. The two perspectives would influence and be developed directly dependent on each other during the process of the project.

Another choice made was that new technology should be implemented and used as a tool to achieve the artistic and pedagogical aims of the project. Mainly because of my interest and experience of using new technology to achieve defined artistic visions in my work as a composer, but also because of my ambition of exploring the potentials of new technology innovations as new pedagogical tools inspiring the development of new pedagogical methods in musical processes. 
The aims of the project were formulated and divided into two perspectives:

1. Artistic perspective:

- Explore the possibilities of using a crowd of non-professional performers including schoolchildren regardless their musical backgrounds integrated with electronic sounds as sources for musical expressions.

- Explore the human voice integrated with electronically processed sounds of the human voice as musical expressions

- Develop new technology innovations to involve non-professional musicians including schoolchildren in the creative processes of music composition and performance to enhance an artistic idea.

- Develop new technology innovations as new music instruments to simplify performance of and enable new musical expressions.

2. Pedagogical perspective:

- Develop new technology innovations as pedagogical tools/ methods to enable non-professional performers including schoolchildren regardless their musical backgrounds to participate in composition and performance processes of advanced music compositions.

- Develop new technology innovations as new music instruments to enable nonprofessional musicians including schoolchildren regardless their musical backgrounds to perform advanced musical structures.

- Draw attention to - and educate about advanced experimental music to a diverse audience by involving non-professional musicians including schoolchildren into the creative processes.

To explore the formulated aims of the project my choice was to work with a methodology inspired by an action research model in three steps -planning, action and analysis of results. Since the idea was that the formulated aims from the two perspectives would influence and be developed directly dependent on each other I divided the project in separate cycles. Each cycle contained the three steps, were the action step of an individual cycle were analyzed affecting the further cycles within the project. Each cycle started with new research questions dependent on the previous cycle. The overall research question, which permeated the whole project was - How to enable non-professional performers to participate in advanced composition and performance practices to enhance an artistic expression?

$V o U$ involved thousands of common citizens of Umeå in the process and collaborations with several organizations and culture/ technology institutions like Norrlandsoperan ${ }^{2}$, Västerbottens Museum ${ }^{3}$ and Interactive Institute ${ }^{4}$. The project was also a part of the Umeå municipality's European Capital of Culture program, which was realized in the year of 2014. Within the project two artistic music compositions: Part I: We Speak Music! (Lind, 2013) and Part III: Everybody Scream!!! (Lind, 2014), two interactive voice recording installations:

$2<w w w . n o r r l a n d s o p e r a n . s e>$

$3<w w w . v b m . s e>$

$4<$ https://www.tii.se/groups/umea> 
The Voice Harvester (True et al. 2012) and U-Paint! (Lind, Yttergren, 2013) and one exhibition with three interactive music instruments: Part II: The Singing Instruments!! (Lind, 2013) were created. The project also included the development of The Max Maestro - an animated music notation system (Lind, 2014), which enables non-professional musicians regardless their musical backgrounds to participate in advanced musical performances with limited time for rehearsal. This article reports from selected parts of this interdisciplinary artistic research project and contributes with new knowledge to the fields of artistic practice and artistic research, more specifically, the fields of animated music notation and participatory art.

\section{Survey of the fields}

\section{Artistic research}

What is artistic research? And what is/are, or is/are there any difference/s between artistic practice and artistic research?. With a background as a freelance composer within the field of contemporary art music those were some of the questions about artistic research raised for me when started working at the Department of Creative Studies, Umeå University in 2011. The Swedish research council defines artistic research as follow:

The point of departure for artistic research is found in the artistic process and works. Research, regardless of art form, is practice-based and includes intellectual reflection aimed at developing new knowledge. The results of artistic research are usually presented both as creations and in written form. ${ }^{5}$

Among researchers within the field, artistic research is defined as a young field in constant development (e.g Arlander 2014, 27). According to Sinziana Ravini the artistic research field has since its genesis been divided into two categories: (1) Those who think artistic research should challenge and incorporate the academic models by playing on the human sciences side of the pitch. (2) Those who think artistic research should be conducted with anti-academic approaches with the premises of art itself (Ravini 2013, 109). Furthermore Mika Hannula, Juha Suoranta and Tere Vadén (2005) emphasize the need for artistic research to develop a research culture suited for the field and not only adopted from other research fields. The opinion of the need for openness to different approaches in artistic research seems to be shared by many researchers (Ravini 2013, 115) and some even claims as Andreas Gedin, artist and PHD in Fine Art: “...artistic research (read art) must be protected against the devastating, self-sufficient apparatus of institutional structures...” (Ravini 2013, 113).

The fact that the field of artistic research is very young and seems to be in constant development could be seen from both a positive and negative perspective. From the positive, an artistic research field in development and open to new methods and theories not yet established by the academia could lead to new innovative forms of research approaches, and from the negative, the not yet fully established methods and theories of artistic research could affect the credibility of the results presented within an artistic research project. In the $V o U$ project I wanted to explore if and how working within an artistic research project and 
adopting a specific methodology would affect my artistic processes and results, and in the contrary I was hoping that the artistic processes within the project could contribute to the development of the increasing field of artistic research.

As the $V o U$ project was my first time formally working within the field of artistic research I saw this project as a pilot for me trying to get a deeper understanding of the concept of artistic research by practically working inside one. Still, I was not open to let a theoretical approach from a methodology accepted within another field in the academia, which not was designed to work with my artistic processes to fully take control of my project. My idea was to use my experiences working as a freelance composer as a fundament and guide my processes within the project by taking inspirations from accepted methods within the academia. Furthermore, as the definition by the Swedish research council states, developing new knowledge to the field/s of artistic practice and/or artistic research was an essential aim of the project.

\section{Participatory art}

My artistic and pedagogical aims to explore within the project fitted well into the context and form of participatory art, which could be described as a concept of art involving participatory elements as: interactive, relational, cooperative, activist, dialogical and community-based art (Kelly, 2014). More specifically a piece of art, which cannot be appreciated and function properly, unless the viewer is physically present in the artwork itself or a performance of it (Novitz 2013). In participatory art the participating people are often referred to as citizens, regular folks, community members, or non-artists and interacts with a professional artist to create the work (Kelly, 2014). In VoU I decided to use the term "non-professional" performers or singers for the participators, because the project involved a lot of students and school children, which were dedicated to different musical practices and therefor could not be seen as "common citizens". The ambition was still that the processes involving participatory elements should be open to anyone regardless their musical background.

In the VoU project I was interested in using some aspects of participatory art in the musical processes, but still maintain the control of the composition process being able to structure the musical material as a composer. The first aspect of participatory art was used in the sound collecting process, which was the fundamental process the artistic idea of the project was built on. The common citizens of Umeå were creating the musical material to be used within the project by interacting with two specially designed voice-recording instruments. Other aspects of participatory art were used in the performance situations of the three compositions created within the project. In the first and the third composition nonprofessional singers with no or very modest score reading knowledge or experiences of following a traditional conductor participated in the musical performances. The second composition was an exhibition with interactive instruments, where the art was created when people interacted with them. The main idea with adopting the concept of participatory art was to explore the artistic and pedagogical aims defined within the project by involving nonprofessional performers into a contemporary art music process, instead of the common use of having professionals especially dedicated to performing contemporary art music. 


\section{Animated music notation}

As the project proceeded the processes were leading towards the field of animated music notation to be able to fulfill the artistic and pedagogical aims of the project. Animated music notation could briefly be described as animated graphics presented on a screen to give performance instructions of a music composition instead of the written traditional western notated musical score. The field of animated music notation could be described as small but emerging. In the web forum Animated Notation Dot Com (Smith, 2015) an attempt of gathering information about the field has been made. The Australian-based composers/researchers Cat Hope and Lindsay Vickery have been working with animated notation in their compositions, building their own Decibel Score Player and written articles on the subject (Hope, Vickery, 2010, 2011, 2013). Jason Freeman is another composer/researcher working with animated notation as well as aspects of participatory art in his projects (Freeman, 2008, 2010, 2013), not to forget the Icelandic composer collective S.L.A.T.U.R ${ }^{6}$ which have worked with animated notation in several projects. From an educational and pedagogical perspective the composer and music teacher Shane Mc Kenna has used animated notation in his compositions as well as a pedagogical tool in school classes to encourage musical collaboration and ensemble performances (Mc Kenna, 2011). Shane Mc Kenna has also developed Dabbledoomusic, (Mc Kenna, Redmond, 2012) a music education application for primary school children.

\section{The Process - Organization and methodology of a complicated process}

\section{Research setting}

In 2011 I got employed as a Creative Director at the Department of Creative Studies (Teachers Education), Umeå University, Sweden. As a composer and musician working within the field of contemporary art music I was used to in my previous work explore my artistic ideas within a defined project. My artistic explorations, which always is a part of my composition process also includes aspects of research, even if they are not always formally expressed and documented. My background as a composer and the initial ideas for the project made me decide that the project should mainly be executed as a practice-based artistic research project, but I was also interested in exploring what my experiences working within the field of artistic research, would do for my composition process and my artistic expression.

The overall process of the project was organized and divided into a number of different cycles, where every cycle had its own internal process. Each cycle was linked together and connected to the overall organization influencing the development of each other's processes. The different cycles within the overall process were defined as: collecting sounds from the citizens of Umeå, experimental choir workshops, electronic sound processing, creative process with students/ children and the composition process. These cycles were leading towards and affecting the development of the novel technology innovations and the three music compositions (I: We Speak Music!, II: Singing Instruments!!, III: Everybody Scream!!!) to be created within the project. 


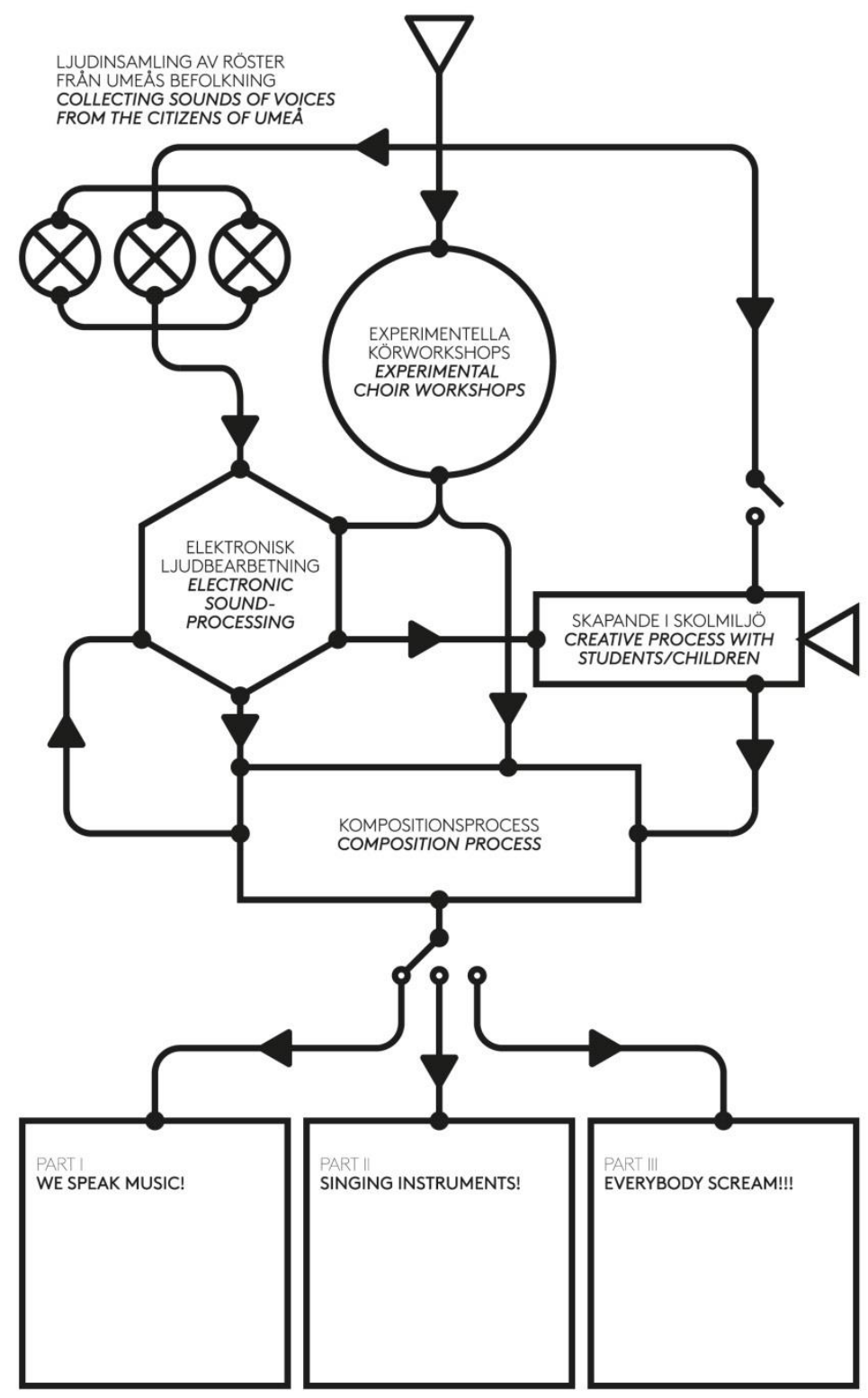

The content of the three compositions, where not initially defined and needed to be open to allow the outputs of the different cycles within the project to affect and make a clear impact. From the artistic perspective: the behaviors of the pedagogical music technology innovations to be created within the project, would affect the process and the artistic outcome of the three compositions, and from the pedagogical perspective: the artistic intentions with the three compositions and reflections from putting the compositions into action, would affect the process and the outcome of the pedagogical music technology innovations.

I needed to have some open lines within the project to fully be able to explore the defined artistic and pedagogic aims and to hold on to the process for the project, but I also needed to have some fixed elements, which would establish the foundation of the project. As stated in the introduction these fixed elements were to: - work with the human voice and electronic processed sounds from the human voice as the only sound source for the artistic outputs 
within the project, -work with the concept of participatory art to enhance an artistic idea in both the composition and performance processes within the project and finally, - work with new technology as a tool to explore the artistic and pedagogic aims defined within the project. Some outlines were also fixed for the three compositions, where the compositions in part I and part III should be concerts exploring the concept of participatory art in performance practice. Furthermore the composition in part II should be an exhibition exploring the concept of participatory art in both composition and performance practices. I chose an artistic theme for each of the compositions: Part I: Speaking, Part II: Singing and leading to the expressive climax and grand finale: Part III: Screaming!. In this article I have chosen to focus on some of the cycles, which I found especially interesting and which had a significant impact on the project as a whole.

\section{Methodology}

The research approach applied within the project can be broadly characterized as artistic (e.g Hannula et al, 2005). The experience, knowledge and skills of me as a composer/researcher were an important source for the analysis of the cycles. Furthermore, the overall ambition with the project was to contribute with new knowledge to the domain of artistic research and practice, by analyzing the results of putting artistic compositions into action. More specifically, the methodology was inspired by an action research approach based on work by Lewin (1958). Lewin's action research process evolves in cycles, each of which includes three key steps: planning, action, and analysis. Being aware of that Lewin's model was created for research within the field of social science my idea was to pick out the parts I considered was best according to the aims of my project. The fundamental idea with action research of putting things into action and then analyzing the results and having the analysis affecting the further cycles within a project suited very well with my intentions. Especially since I needed to explore an approach, which enabled non-professional performers/singers to participate in advanced musical composition and performance processes, which I did not knew of yet. However, my intentions was to explore the artistic possibilities which arises in these settings and not to observe social behaviors of a group in a social experiment, which was my reason to base the methodology on some of the outlines of Lewin's action research model. The actual implementation of the model was different for each of the cycles, but the template I used was defined as follow: 


\begin{tabular}{|l|l|}
\hline Step 1: Planning. & $\begin{array}{l}\text { Considering my previous knowledge and experiences as a } \\
\text { composer, considering analysis of results from other cycles within } \\
\text { the project, inspiration from other related works, composing } \\
\text { processes, building processes, planning processes. }\end{array}$ \\
\hline Step 2: Action. & $\begin{array}{l}\text { Performances/Exhibiting's of the three compositions within the } \\
\text { project (2 Concerts and 1 Exhibition), the workshop sessions, putting } \\
\text { the voice recording installations in public. }\end{array}$ \\
\hline Step 3. Analysis of results & $\begin{array}{l}\text { Analysis of results of step 2. (The analysis of results would affect the } \\
\text { step 1 in another cycle within the project) }\end{array}$ \\
\hline
\end{tabular}

Each cycle started with new research questions, which was defined dependent on the analysis of the previous cycles. Audio recordings were made of the action steps to enable analyzing the artistic output of each cycle. The experiences of myself participating as a composer, performer and researcher in the action steps were also included as data in the analyzing processes. As a result of me being the composer, performer and researcher in the project my previous artistic knowledge and experience also had a significant impact on the analysis of results.

\section{The Voice Recording Instruments - Collecting sounds of voices from the citizens of Umeå}

The fundamental idea was to start collecting sounds of voices from the citizens of Umeå and create a large electronic sound bank with different voices, which later could be used as the main musical material for the three compositions to be created within the project. For the voice collecting process two voice recording instruments where created in collaboration with a team from Interactive Institute in Umeå. The aim with the two instruments was to engage and inspire the citizens of Umeå to participate in the project and record their voices by interacting with the instruments. As a composer I found the idea to use aspects of participatory art to collect the fundamental music material for a composition very interesting. By adopting this method I was inviting the citizens of Umeå to create the fundamental music material for the project by using their voices. My role together with the team from Interactive Institute was to create a novel music technology innovation as an artistic and pedagogical tool to inspire the citizens to participate and make their best effort in creating unique, personal and interesting sounds with their voices. Initially I was interested in getting sounds, which were expressive, naïve and personal. Two main research questions were asked to start the development of the first voice recording instrument: (1) How do we get people to be engage, inspired and most important to interact with the instrument? and (2) How do we get people to make expressive, nä̈ve and personal sounds without inhibitions? 


\section{The Voice Harvester}

Step 1: Planning. Based on my own experiences from collecting voices in a previous project (Lind, 2008) I knew some of the crucial issues we needed to deal with to be able to collect the voices as intended. The experiences from the team of Interactive Institute working with this kind of public installations also was important in the planning process. (Fällman, 2003, 2008) The voice is a very personal instrument and even if it is used in our everyday communication with the world around us, we are in general shy to use our voice in expressive ways in public. We needed to approach the citizens with an instrument, which would engage them to go beyond their comfort zone to experiment and explore the full potential of their voices. The instrument should inspire the people to make intuitive and naïve sounds with their voices, without feeling awkward or embarrassed, which certainly would affect their interactions with the instrument. Ideally I wanted to have personal unique recorded sounds of voices from a diverse group of people, in terms of age, musical background, gender, social groups and so on...

The Voice Harvester finally took shape as a free-standing, interactive voice recording instrument. This physical, interactive installation was created to provide direct feedback in a physical, tangible form to whatever sounds the user fed into it (True et al. 2013, 3004). Three microphones were connected to a computer with a pre-programmed Max/MSP ${ }^{7}$ stand alone application, which processed the input signal from the microphones and output it to three speakers. When the users altering their voices in terms of pitch and volume the installation would respond with immediate feedback. Three acrylic tubes containing three different materials were attached to the three speakers and when sound came out from the speakers the materials started to move. The material used for the three tubes were paprika powder, blue glitter and water with red cochineal (True et al. 2013, 3005).

Step 2: Action. The Voice Harvester was exhibited in various public spaces in Umeå to meet the citizens, starting in the beginning of 2013. A press release was handed out to various media in Umeå, announcing the start of the voice collecting process and inviting the citizens of Umeå to participate in the project. The Voice Harvester was first exhibited in various places at Umeå University, before the first evaluation of the recording process.

7 A visual programming language for media used by composers and artists experimenting with sound and other media. https://cycling74.com/products/max/ (2016-02-10) 


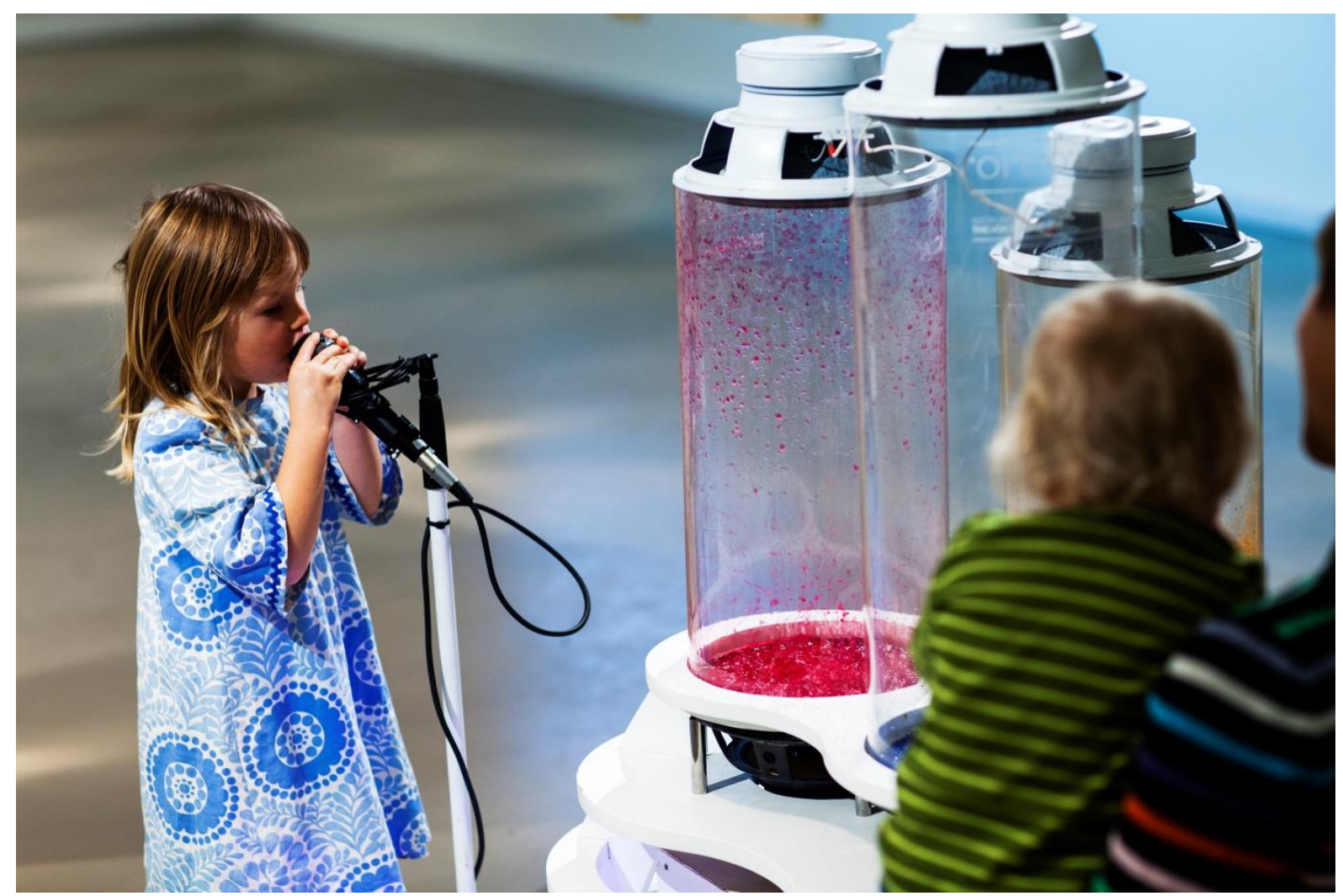

'The Voice Harvester' (photo: Elin Berge)

Step 3: Analyses of Results. The sounds recorded by the Voice Harvester and my experiences participating as a workshop leader, composer and researcher in the action process were used as the main data for the analyzing process. The Voice Harvester had between 7 February and 1 March been exhibited at Umeå University and collected about 2000 sound files. The content of the files consisted of sounds of voices with varied length from 30 seconds to 5 minutes, which I had programmed as a limit for the recording length. The various lengths of the files indicated that some people stayed to explore the instrument longer and some were just contributing with a short sound. As a composer the amount of files and the content from an artistic perspective collected this far was beyond my expectations. The Voice Harvester seemed to generate sounds, which were loud, raw and expressive, often with no absolute pitch. Different screams were commonly found and also noises made on consonants as: schh, $k$, fff... and short non-linguistics letter combinated words as: Ba!, Te! and Kå!... I realized at this point that I also was in need of other music material to get a more dynamic and varied sound bank of voices. Taking part in the actions of the process also made me realize that The Voice Harvester was not suited for all public spaces. The installation was quite loud, which was disturbing people in the near surroundings not interacting with the installation. The analyses were summarized with two research questions for the development of the second voice recording instrument: (1) How do we create a voice recording instrument, which would inspire people to make sounds with definite pitches and various amplitude? and (2) How do we create a quiet voice recording instrument, which not is disturbing for the surroundings not interacting with it? 


\section{U-Paint!}

Step 1: Planning. The U-Paint! Instrument was developed based on the experiences and analyses of results from the cycle of The Voice Harvester. The initial idea was to create an interface, which could visualize definite pitches made by the human voice to inspire the citizens to use their whole register of their voices in terms of definite pitches. The first idea was to create a videogame, which would be controlled by the human voice in terms of pitch and volume, but in the process we realized that the game would be hard to play for people with no musical background. Finally we ended up with an idea for an interface, where the people could create unique paintings using the human voice in terms of pitch and volume together with tweaking knobs on a custom made interactive palette. The ambition was to inspire the citizens to make sounds containing definite pitches in various dynamics to be included and stored in the sound bank of voices within the project.

Step 2: Action. The U-Paint instrument was first exhibited and put together with the Voice Harvester at the MADE festival at Norrlandsoperan in May 2013. The festival was a three days event, involving experimental music artists and hundreds of people in the audience. The first recording process of the U-Paint! was evaluated after the festival.

Step 3: Analysis of Results. The sounds recorded by the The U-Paint! were used as the main data to be analyzed. 240 sound files had been collected by the U-Paint! instrument by comparison to 687 sound files collected by The Voice Harvester during the same festival. The audio contents of the files were more balanced and included mainly sounds with definite pitches in various amplitudes as expected. Different glissandos in various registers where commonly found. As a composer I found the sounds really inspiring and also a good compliment to the characteristics of the files collected by the Voice Harvester. The analysis of my own experiences interacting with U-Paint! made me to remove a sound element, which not seemed to make any difference for the experience using the instrument.

The Voice Harvester and The U-Paint! Instruments continued their tour during the year of 2013 to collect the sounds of voices from the citizens at various public spaces in Umeå. In the end they had been exhibited in places like Umeå University, Norrlandsoperan, Nolia-Mässan ${ }^{8}$ and Västerbottens Museum and the electronic sound bank of collected voices from the citizens finally reached over 10000 sound files. Nevertheless, it was impossible to say exactly how many people were involved in the collecting process, because one person could obviously record several files. The recorded sound files were later picked out and processed to be the fundamental music material in the three compositions created within the project.

8 A big public event and trading post in the north of Sweden including 500 exhibitors and approximately 100 000 visitors during 9 days in August each year. 


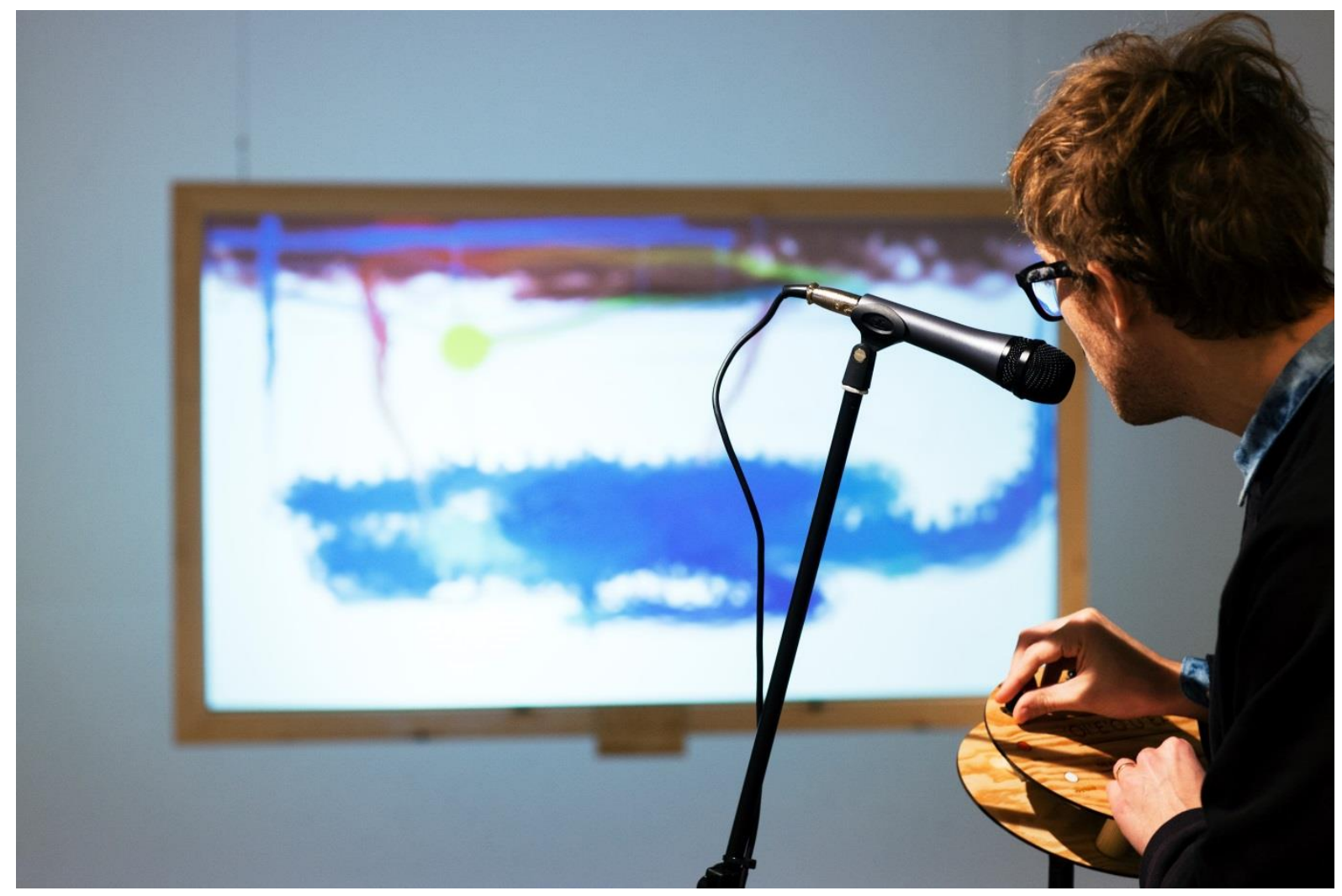

\section{The three compositions}

\section{Artistic visions}

The overall artistic ideas for the three compositions were a reflection of my ideas and visions as a composer. Initially in the project I had fixed some elements to be explore as artistic material for the compositions. These elements were divided into four categories, which is further explained in the article/exposition: New artistic possibilities with The Max Maestro an animated music notation system for non-professional performers: (Lind, 2015)

1. Performers: Crowd of non-professionals

2. Instruments: Human voices and novel music technology innovations

3. Sounds: Human voices and electronically processed Human voices

4. Musical material in focus:

4.1 Polytempo textures

4.2 Static and moving approximate pitch cluster textures

4.3 Noise formation textures

4.4 Rhythmical text canon

4.5 Rhythmical accents

\section{Pedagogical visions}

The pedagogical ideas were different in each of the three compositions. In the first and the third composition the idea was to develop a novel music technology innovation as a pedagogical tool to enable the performances in the concert situation. Both as a pedagogical tool replacing the traditional conductor and also as a pedagogical tool replacing the traditional music notation system. The novel music technology innovation as a pedagogical 
tool should make the musical material to perform understandable for the performers and also to be able to guide them through the musical performance. In the second composition the idea was to create a series of novel music technology innovations as interactive music instruments. The ambition was to develop the instruments as pedagogical tools, which would enable nonprofessional performers to compose and perform advanced musical structures within the field of contemporary art music.

\section{Part I: We Speak Music! - A composition including a pilot of an electronic conductor system}

Voices of Umeå Part I: We Speak Music! was the first composition to be performed within the project. It was premiered by 40 students from the Department of Creative Studies, Umeå University together with electronically preprocessed sounds of voices through a multichannel speaker system. The composition was for me seen as a pilot composition, where the concept of participatory art was adopted in the performance situation. The idea was to use the recorded and processed sounds from the citizens of Umeå together with non-professionals with no or very modest score-reading knowledge and no or very little experiences of following a traditional conductor as performers on stage. The process of this pilot composition was the first step of the development process for a pedagogical music technology innovation, which later in the project was leading towards the development of The Max Maestro - an animated notation system. As previously described in the process section The artistic ideas and intentions with the composition would affect the development process of the pilot pedagogical music technology innovation and in the contrary: - The pilot version of a pedagogical music technology innovation and its behaviors and possibilities would affect the artistic outcome for the composition. The initial artistic vision for We Speak Music! was to take advantage of the rich capacities of the human voice as a sound source and the possibility to create advanced musical textures in a group of non-professional performers. By performing individual patterns with simple to execute sounds made by their voices and integrating these with electronic pre processed sounds advanced musical textures could be created. The main questions to start the cycle were:(1) How to synchronize the group of people with the electronic sounds? and (2) How to conduct the people with the right performance instructions through the composition?..." (Lind, 2015)

Step 1: Planning. The composition process started with examining the content of the electronic sound bank of voices collected by the two voice recording instruments. At this time about 2000 sound files were collected and only by the Voice Harvester, since the $U$ Paint! Instrument was first exhibited the day after the premiere of We Speak Music!. In general the sounds were very fascinating and abstract, with an expressive and often loud artistic expression. It was interesting to cut out small parts of the sounds and further process them and combining to complex musical textures or new individual percussive sounds. The method of using the voice recording installation to collect the sounds seemed very exciting, because I couldn't imagine any other way of getting these types of sounds, by instructing a performer or singer verbally. However, I realized that the huge amount of sound files were impossible to examine by myself, which demanded for a method to sort out the most interesting sound files. I decided to concentrate on the recorded files with the biggest size - 
longest duration, with a thesis that the longer the recording session with the instrument was, the more inspired and interesting from an artistic perspective the voice interaction would be. Sounds of people speaking were also one of the artistic inputs for the composition. To complement the electronic sound bank I made field recordings of people speaking by instructing them to read a text from Wikipedia about Umeå into my handheld microphone.

The composition process was dependent on the development of the pedagogical music technology innovation, which first pilot in this project was inspired by similar systems I had developed in my previous works (Lind, 2009, 2011). The pilot innovation was also inspired by other composers as John Cage (e.g. Cage, 1991) and his methods of using a common clock to synchronize performers within an ensemble instead of a human traditional conductor. The idea at this point was to have a system, which would work as an electronic conductor leading the non-professional performers through the composition and having the ability to synchronize them with the electronic sounds for the composition. With the We Speak Music! composition I wanted to test, which types of musical material was best suited for the group of non-professional performers and the electronic conductor system. My thesis was that different musical textures as polytempo and various cluster and noise textures were better suited for the system than synchronized rhythmical structures and beats. The idea was also to test how much rehearsal time was needed, when using the electronic conductor system and the intended group of people for the performance. A mixed model between using the electronic conductor system and written notation on papers was finally used for the composition. The notation consisted of 37 blocks, with new musical instructions in each block. The length of each block was specified by a timeline (Lind, 2015). A mixture of text and graphical elements inspired by approximate graphic notation (e.g Penderecki, 1960) and the use of boxes to describe individual tempo performance (e.g Lutoslawski, 1964) were used in the notation. 
4

13

M

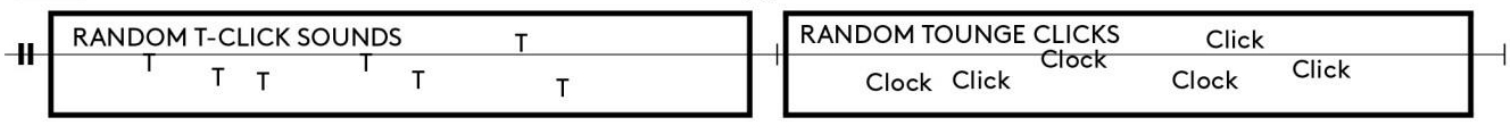

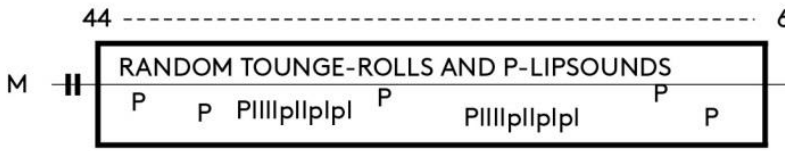
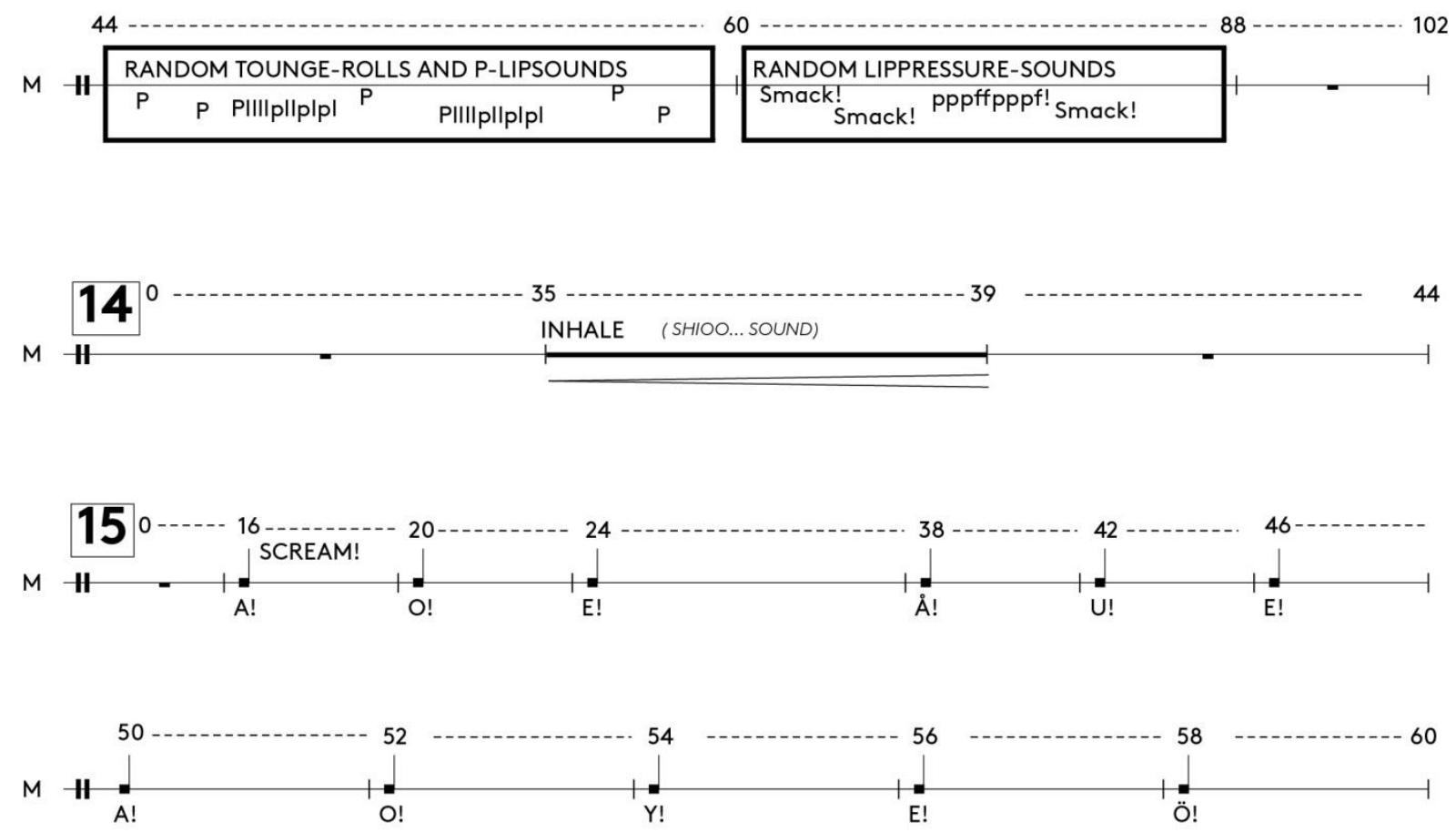

16 144 BPM

M

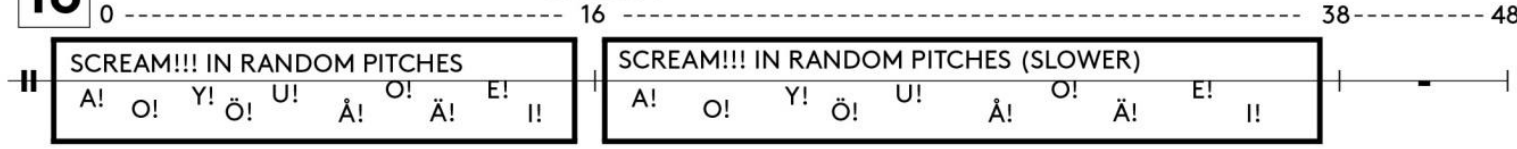
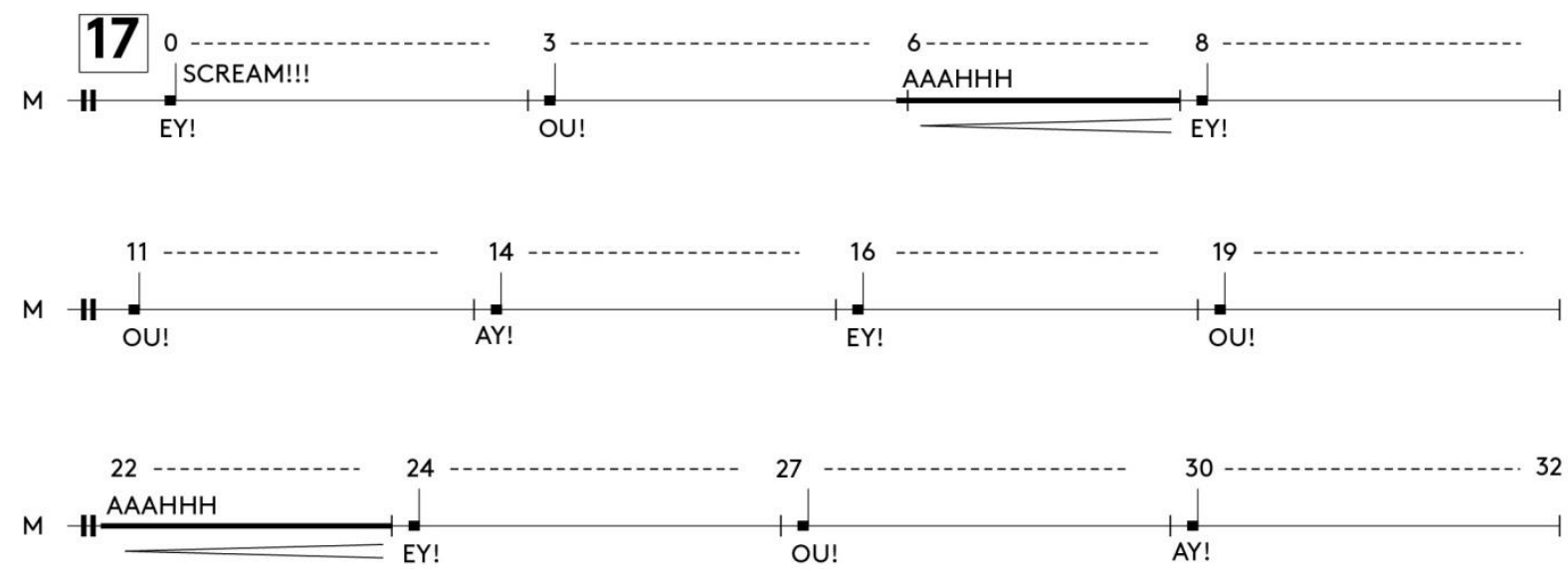

Score for We speak Music! 
The musical material of the composition included sound textures of speaking voices, which was structured in different layers according to their individual pitch registers, polytempo textures, noise formation textures, rhythmical structures and rhythmical accents. Aspects of spatialization of sounds, were also considered in the performance using a 16-channel speaker system.

Step 2: Action. The premiere of Voices of Umeå Part I: We Speak Music! was performed at Ljusgården, Umeå University by 40 students and electronic preprocessed sounds of voices through a multichannel speaker system. The concert was a collaboration with the MADE festival of Norrlandsoperan and it was broadcasted in selected parts by the Swedish Radio P2. The composition had a total duration of 19 minutes and was conducted by an electronic conductor system developed in Max/MSP as a pedagogical tool.

Step 3: Analysis of results. The audio recording of the concert and my experiences participating as a workshop leader, composer and researcher in the action process were used as the main data for the analyzing process. Four workshop/ rehearsal sessions of 90 minutes each, were preceding the performance. The group of students was able to perform the musical ideas as intended, but some questions were raised. Two major problems were formulated: (1) Hard for the students to remember the musical instructions explained in the written notation, and (2) Too much rehearsal time needed for preparing the performance." (Lind, 2015)

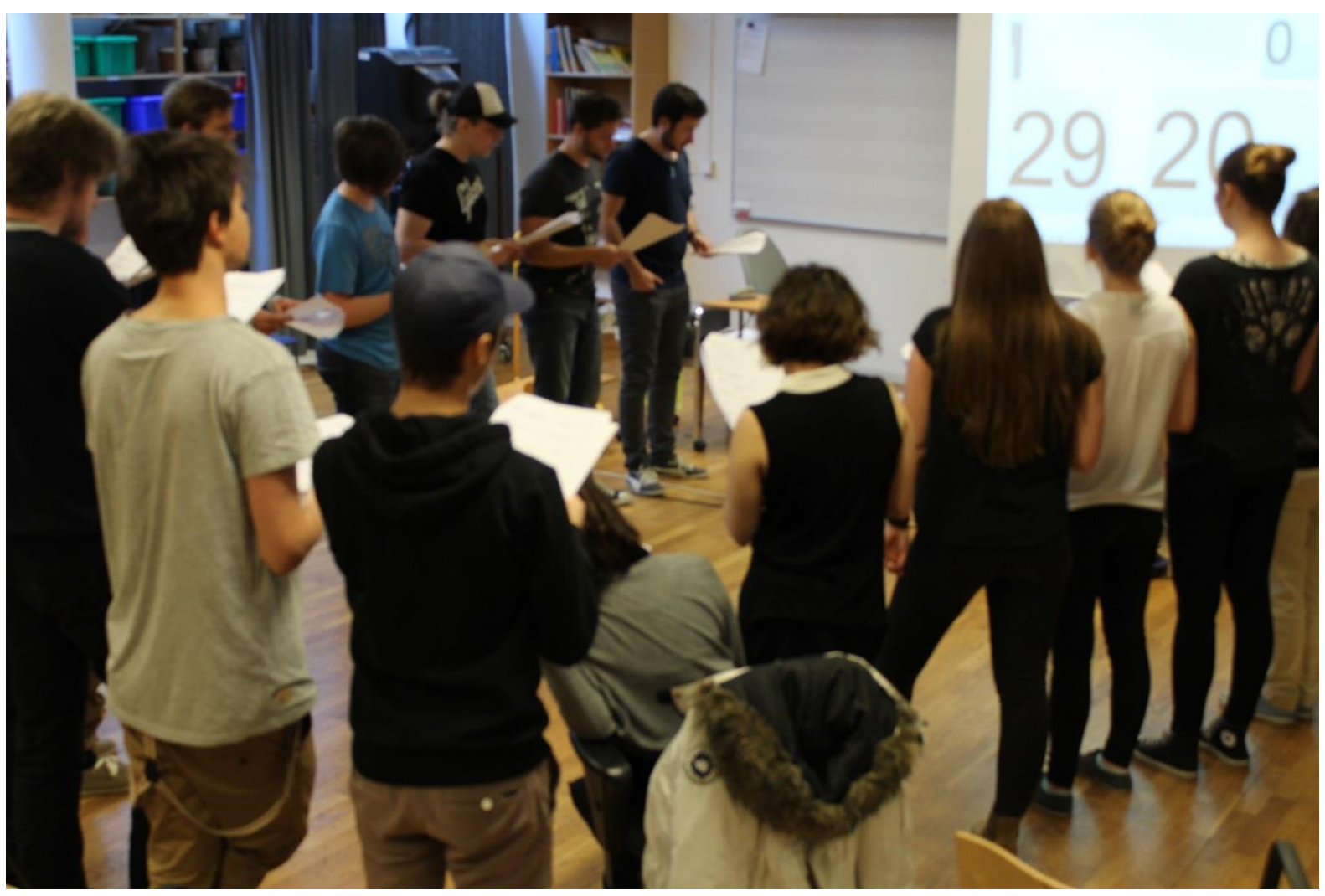

The analysis of result was taken into consideration for the composition process of the third composition and the development process of a new pedagogical tool. 


\section{Part II: Singing Instruments!! - Everyday objects becomes novel music instruments to encourage participatory art}

The second artistic composition within the project was an exhibition with a series of novel music technology innovations as interactive music instruments. Voices of Umeå Part II: Singing Instruments!! was created to explore the concept of participatory art adopted both in a composition and performance situation. The idea was to develop an intuitive platform, by using new technology and knowledge from the fields of artistic and educational practices, where people regardless their musical backgrounds could compose and perform advanced musical structures. From the pedagogical perspective the instruments were developed to encourage workshop sessions with schoolchildren, learning about fundamental musical parameters and concepts of composition and performance practices by performing advanced musical textures together, and from the artistic perspective the instruments were developed to enable new musical expressions and to visualize the electronic sounds in a performance. The ambition was to create a series of instruments, which anybody regardless their musical background could master at first sight. In contrary to acoustical music instruments used in traditional ensemble and orchestra settings, which demands years of training before you can get to the point of what musical performance is about: - Musical interaction (Myllykoski et al. 2015). The main research question for the development of Singing Instruments!! was: How can an intuitive music instrument be developed that: first-time users can quickly master, encourages new musical expressions, and facilitates participatory art?

Step 1: Planning. The ideas for the exhibition were initially based on my experiences as a composer within the field of contemporary art music. I wanted to develop a series of interactive instruments, which would be intuitive and playful but at the same time a relevant tool for professional exploration of new musical expressions. The initial idea was to work with everyday objects, which we interact with in our everyday life and connect the natural behaviors and the symbolic meanings of these objects to musical parameters. My thesis was by using everyday objects as new physical controllers for musical sounds the main research question could be answered. From the pedagogical perspective the use of everyday objects as interactive instruments would enable everybody regardless musical background to use them and make way for practice-based workshop sessions to educate about aspects of musical performances, and from the artistic perspective the absence of performance tradition routed in these interactive instruments probably would inspire and contribute to the development of new musical expressions (Lind, Nylén, 2016). Furthermore I decided to work with four fundamental musical parameters and connect one or two of these for each of the three instruments: Pitch, Rhythm, Amplitude and Timbre. By limiting the control of each instrument to one or two musical parameters the idea was to better serve the artistic and pedagogical aims for the instruments. From the artistic perspective the limitation would probably inspire and make way for innovative use of the few parameters available with new artistic expressions as a possible result, and from the pedagogical perspective the limitation would enlighten these musical parameters with an aim to educate about fundamental elements of music.

Four washbasins with taps, four bicycle wheels with a skateboard and a dresser with seven drawers were the final selection for the everyday objects to use for the instruments. Next in 
the process I examined which types of sensors and electronic components was suitable for transforming the natural movements of the objects into electronic data. The sensors and components I finally ended up with were: analog distance sensors for the dresser with seven drawers, digital reed sensors and magnets for the five bicycle wheels and ordinary potentiometers for the washbasins with taps. The everyday objects were the main controller interfaces for the instruments together with an additional control panel with some buttons and potentiometers to change sounds and for extra sound adjustments. To make the sensors communicate with the computer an arduino ${ }^{9}$ board was connected as a bridge between the sensors and the computer. The output signals of the sensors and the electronic components went through the arduino board and into a preprogrammed standalone application made in Max/MSP, which transformed the signals into actions controlling the sounds of the instruments. All the sounds of the instruments were taken from the electronic sound bank of voices collected by the two voice recording instruments within the project. The three instruments were supposed to encourage collaborative musical composition and performance processes and were structured and named after different ensemble setting definitions. The four bicycle wheels with the skateboard became the Wheel Quintet, the four washbasins with taps became the Tap Quartet and the dresser with seven drawers became the Drawer Septet.

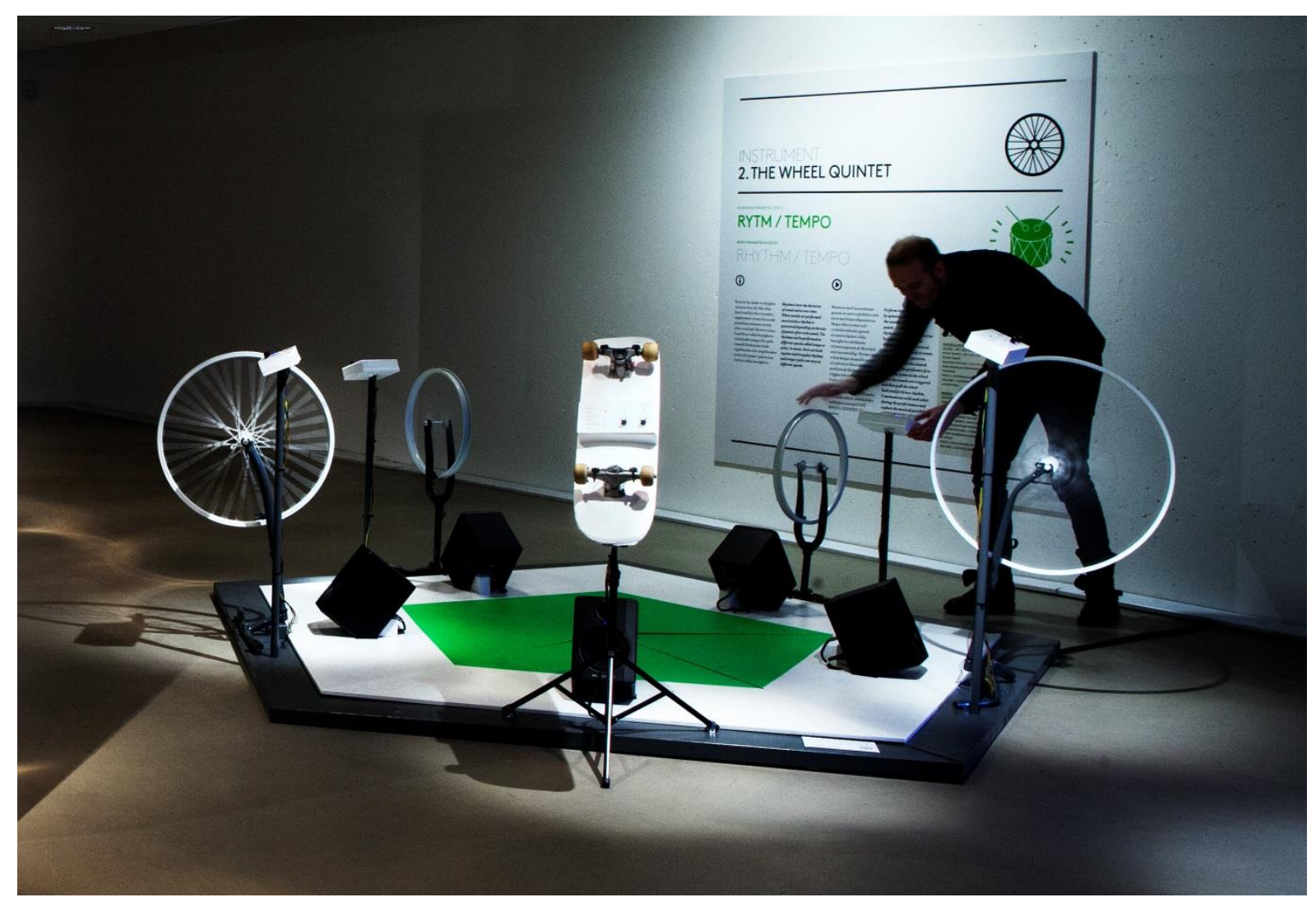

'The Wheel Quintet' (photo: Elin Berge)

\section{The Wheel Quintet}

1-5 performers, musical parameters in focus: Rhythm/ Tempo

9 Arduino is an open-source electronics platform based on easy-to-use hardware and software. It's intended for anyone making interactive projects. < https://www.arduino.cc> 
Perform with the instrument by spinning the wheels and mix the sounds with the control panels. Create different rhythms and rhythmic patterns by spinning the wheels at different speeds. Spin several wheels simultaneously to create advanced rhythmic patterns. Rhythms can also be created manually if the performer first locates the point on the wheel where the sounds are triggered and then pull the wheel back and forth in a rhythm. Communicate with each other during the performance and explore the musical possibilities of THE WHEEL QUINTET. $^{10}$

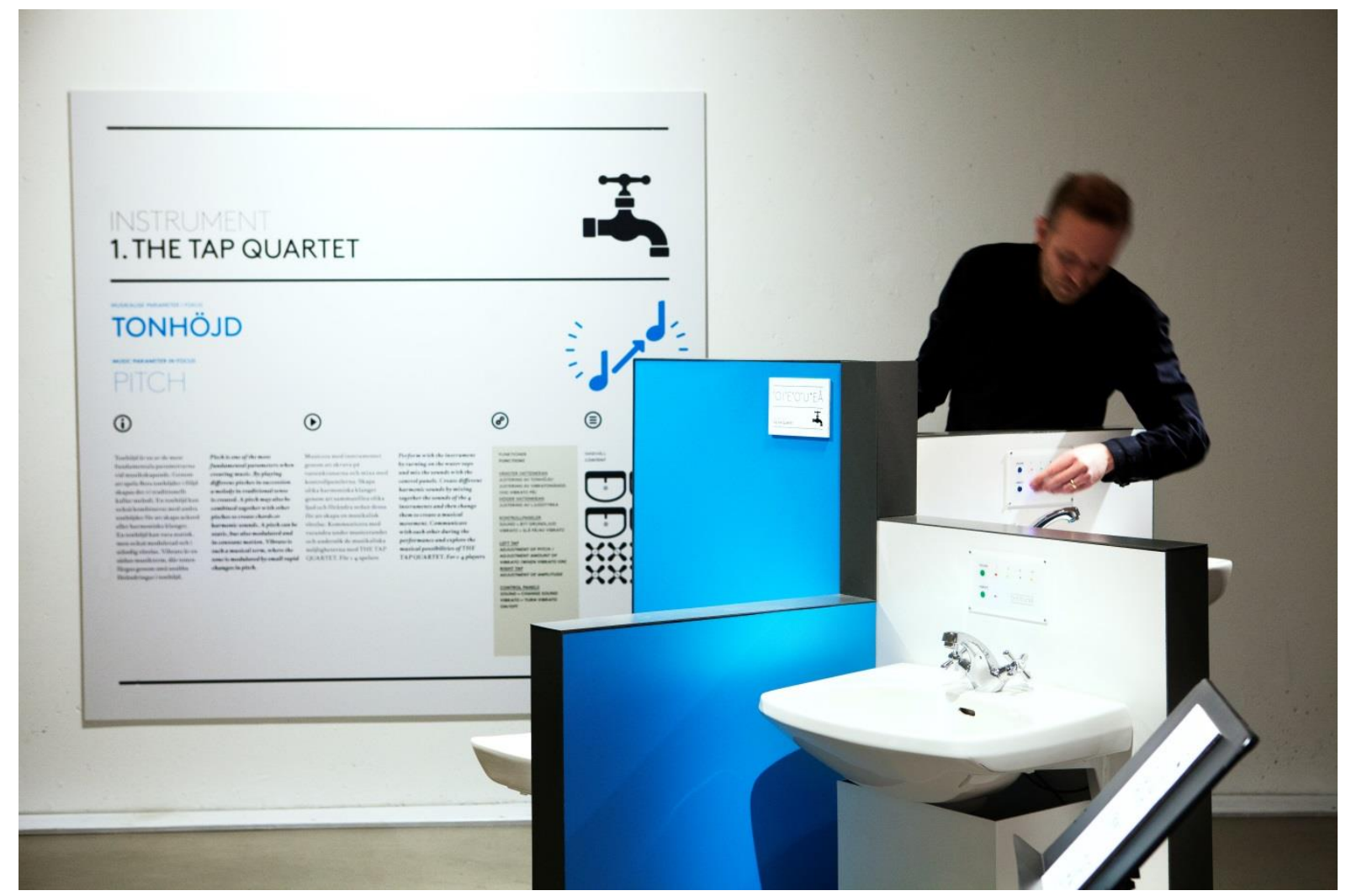

'The Tap Quartet' (photo: Elin Berge)

\section{The Tap Quartet}

1-4 performers, musical parameters in focus: Pitch/ Amplitude

Perform with the instrument by turning on the water taps and mix the sounds with the control panels. Create different harmonic sounds by mixing together the sounds of the four instruments and then change them to create a musical movement. Communicate with each other during the performance and explore the musical possibilities of THE TAP QUARTET. ${ }^{11}$

10 Information text for The Wheel Quintet taken from the exhibition Singing Instruments!! 11 Information text for The Tap Quartet taken from the exhibition Singing Instruments!! 


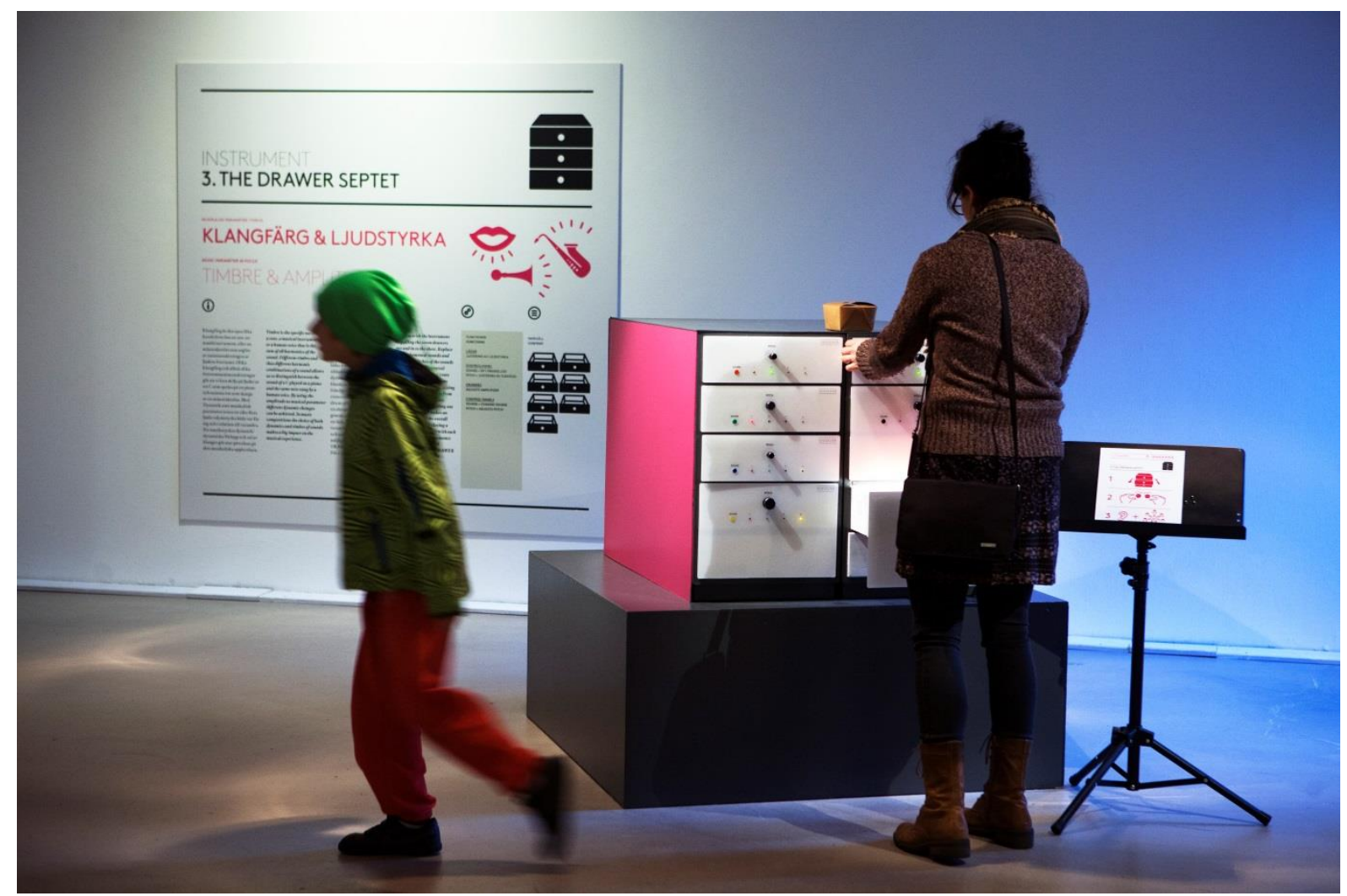

'The Drawer Septet' (photo: Elin Berge)

\section{The Drawer Septet}

1-7 performers, musical parameters in focus: Amplitude/ Timbre

Perform with the instrument by pulling the seven drawers out and in to the chest. Replace the fundamental sounds and adjust the pitches of the sounds by mixing with the control panel on each drawer. Create different timbre formations and dynamic changes by mixing and changing the sounds from the chest. Make a dynamic crescendo by slowly pulling out different boxes, or makes an abrupt change of the overall timbre by suddenly closing a drawer. Communicate with each other during the performance and explore the musical possibilities of THE DRAWER SEPTET. ${ }^{12}$

Step 2: Action. Voices of Umeå part II: Singing Instruments!! was exhibited from $29^{\text {th }}$ September to $24^{\text {th }}$ November in 2013 at Västerbottens Museum in Umeå, Sweden. The exhibition with the three instruments of everyday objects also included the two voice recording instruments; The Voice Harvester and U-Paint!, which were continuing collecting voices from the citizens for the third and final composition within the project. From a composer point of view I tested different artistic possibilities with the instruments during the exhibition period. The action process also included workshop sessions where schoolchildren were invited to participate in exercises involving the instruments and graphic scores. ${ }^{13}$ The workshop sessions were executed with four different school classes together with music teacher students from Umeå University and myself as a supervisor. The length of each

12 Information text for The Drawer Septet taken from the exhibition Singing Instruments!!

13 Graphic notation is the representation of music through the use of visual symbols instead of traditional music notation. Famous example of a graphic score is December 1952 by Earl Brown. <

https://www.youtube.com/watch?v=WlGkaP4u2cw> 
workshop was 50 minutes and the participating school classes were two classes from the $3^{\text {rd }}$ grade and one class each from the $6^{\text {th }}$ grade and the $9^{\text {th }}$ grade. The ambition with the workshop sessions was primarily to explore the possibility of performing advanced musical structures with school children by using the Singing Instruments!!. Specific musical structures used in the workshop sessions were; poly-tempic textures and different timbre and pitch cluster formations. The exercises were specially designed to work with the three instruments. Each instrument got a specific graphic score, which was conducted by a student or myself.

The Wheel Quintet exercise example:

One or two pupils were situated in front of one station including one wheel or the skateboard of the instruments total of five stations forming a quintet - The Wheel Quintet. A graphic score in five individual parts were the written instructions of the musical exercises to be performed together. Four exercises were designed for each instrument and the complexity factor was increasing for each exercise. The musical content within each exercise were divided into separate numbered actions, which the school children should trigger by following directions from the conductor. The conductor (student or myself) was triggering the separate actions by holding up the number of fingers, depending on which action he or she wished to trigger. The actions could be: spin the wheel fast, stop the wheel or spin the wheel slow and increase the volume at the same time. By having the five performers spinning the wheels in different tempos and instructing them to spin at various speeds, changing sounds and volume in different combinations various advanced rhythmic patterns and poly-tempo textures could be performed.

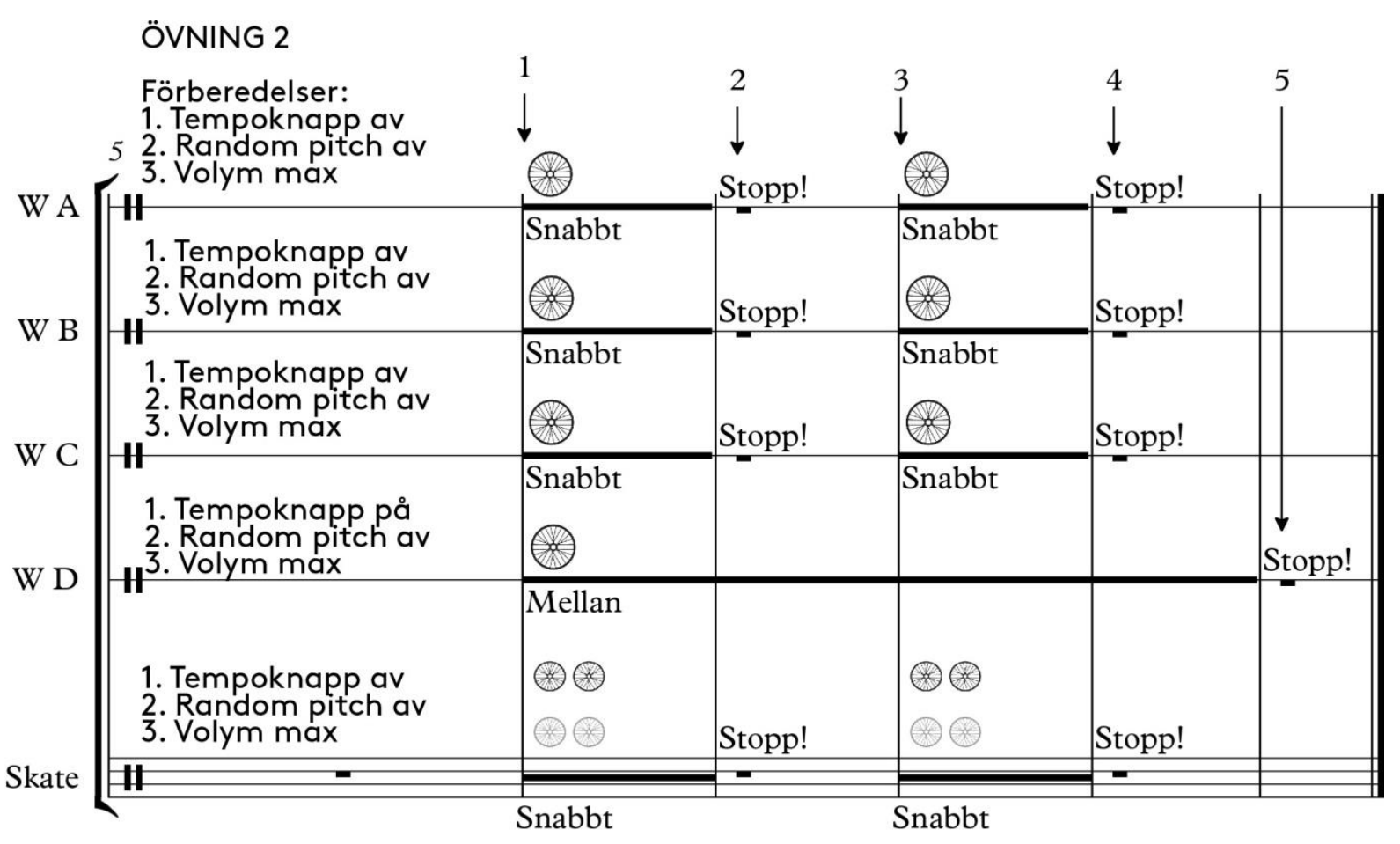

Exercise for the Wheel Quintet 
Step 3: Analysis of Results. The experiences of myself participating as a workshop leader and composer were the main data to be analyzed. The Singing instruments first meeting with the general public made me realize that some of the construction needed to be stabilized. Already on the opening vernissage the interactions caused some damages on some of the instruments, especially on The Tap Quartet. The issues were adjusted with help from Interactive Institute. The exhibition seemed to be appreciated by the general public, especially among families with children. Different behaviors among the people interacting with the instruments was noticed, which I organized into three categories. (1) Playful interactions where the behaviors of the instruments were explored as a game, with no reflection of being part of a musical process. (2) Playful interactions where the behaviors of the instruments were explored as a game but also as musical instruments. (3) Playful interactions where the behaviors of the instruments were explored as primarily musical instruments.

The experiences of participating in the workshop sessions were analyzed and even if the amount of data collected not was enough to point out any absolute results they indicates that these types of interactive instruments are relevant both from an artistic and pedagogical perspective. With only 50 minutes of actions with the instruments the schoolchildren in all of the grades could perform quite advanced musical textures, which would be hard to perform with traditional ensemble or orchestral instruments. By using these types of intuitive interactive instruments the school children could immediately get to the point of musical interaction and collaboration, which would be impossible if using traditional ensemble or orchestral instruments.

As a composer, the ability to test and explore different theoretical composition ideas by physically interacting with the instruments and hearing the sounding results was very rewarding from an artistic point of view. The possibilities of creating different advanced musical textures with the instruments were taken into the planning process of the third and final composition within the project.

\section{Part III: Everybody Scream!!! - A large scale music composition with animated music notation}

The third and final composition within the project was a concert involving elements from all of the other cycles within the project. The concert was seen as the grand finale of the project and was scheduled to be a 45-minutes composition involving three hundred and fifty nonprofessional singers, three interactive instruments, a novel music technology innovation as a conductor and thousands of pre-processed voices from the citizens of Umeå. The idea was to further explore the concept of participatory art in the performance situation. The major research questions to be solved, which had been processed through the whole project, to accomplish the artistic vision were: (1) How to enable non-professionals to perform advanced musical structures in sync with an electronic music part?, and (2) How to conduct and instruct a large crowd of non-professional performers through a 45-minutes composition but with very limited rehearsal time? 


\section{The Max Maestro - an animated music notation system}

Step 1: Planning. The idea of developing an animated music notation system was grown as a result of the analyses of the previous cycles within the project. Especially from the cycle of We Speak Music! and the workshop sessions, which were executed with school children within the project. The development of the system was also a result of my experiences as a composer and influenced by other animated notation system created by other composers (Smith, 2012, Pálsson, 2012, Hope, Vickery, 2011 et al.). The idea, which had grown within the project was to create a system more inspired by intuitive music video games as Sing Star (2004) or Guitar Hero (2005) than traditional or extended music notation systems. Mainly because of my thesis that the target group of non-professional performers including school children in general are more familiar with videogames than musical notated scores and as Rui Rolo (2011) puts it: “... fun games increase learners motivation and foster collaboration, crucial issues in music practice.". Based on the experiences from the cycles within the project I made a pilot version of an animated music notation system, which first was tested in workshop sessions with music students at Umeå University.

This version was organized into four rows in different colors, which made it possible to divide the crowd of performers into four sections. Each section should follow the animated graphics presented on their row, which symbolized specific musical performance instructions.

The performance instructions included which fundamental sound to produce with their voices and approximate pitch and amplitude for the sound. Furthermore the duration of the sound was also included in the instructions. ${ }^{14}$ The performance instructions in terms of pitch and amplitude was approximate, were the defined frame was the capacity of each performers individual voice.

14 More information about The Max Maestro could be found in the videoclip: https://www.youtube.com/watch?v=4iePLi5uQzU and in the article/exposition: New artistic possibilities with The Max Maestro - an animated music notation system for non-professional performers: (Lind, 2015) 


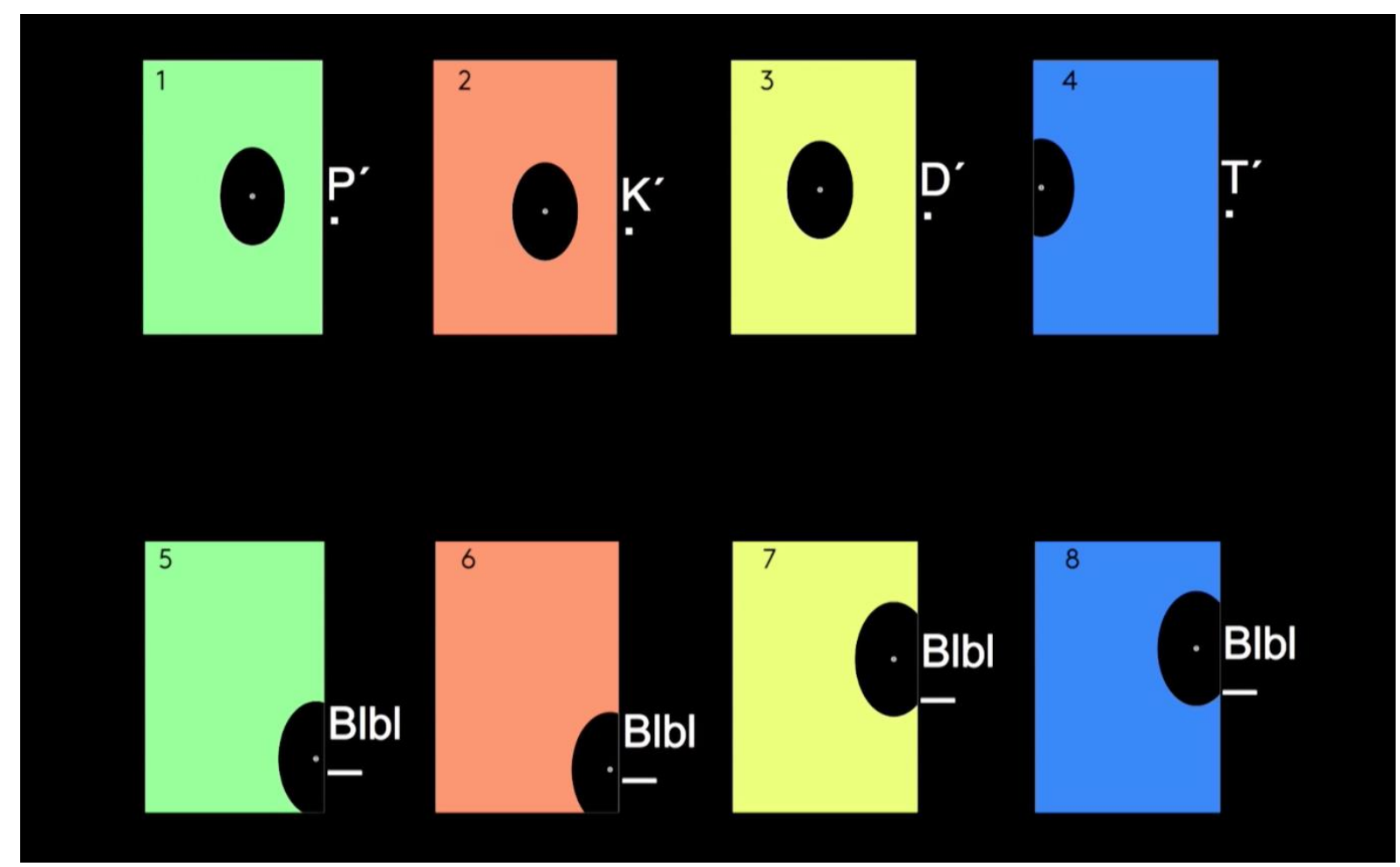

Screenshot of the Max Maestro

Step 2: Action. Two workshop sessions were held involving tests of some musical ideas in the form of exercises with the animated music notation. The students were instructed to make sounds with their voices by following instructions from the animated music notation, which was projected on a screen in a standard classroom. Some of the exercises included electronic sounds and some was without. The exercises included musical material as: Polytempo textures, Static and moving approximate pitch cluster textures, Noise formation textures, Rhythmical text canon and Rhythmical accents.

Step 3: Analysis of Results. Audio recordings of the workshop sessions were used as the main data to be analyzed. The people involved in the workshop sessions were music students dedicated to the popular music field, meaning that they in general were used to play together by ear and not by reading instructions from a traditional notated score. Furthermore they had no or very modest experiences of following instructions from a traditional music conductor. Those were two reasons why I used them as a reference group for the aimed target group of performers for the composition. The pilot animated music notation system seemed to be very intuitive to follow. All of the texture-based musical materials were performed with interesting results. The rhythmical musical materials seemed to be more difficult to perform. Some minor changes for the visual output of the system were made as a consequence of the analysis. Furthermore, the final version to be used for the performance of Everybody Scream!!! included performance instructions for eight individual parts.

\section{Everybody Scream!!! - The grand finale composition}

Step 1: Planning. The composition process had been going on along with the different cycles within the project and the analysis of results from the other cycles had affected the composition process in different directions. The fundamental music material was taken from the collected electronic sound bank, which now had reached over ten thousand files of voices 
from the citizens of Umeå. I used the same selective process for the electronic sounds as in the earlier processes for We Speak Music! and Singing Instruments!!. In this composition I decided to include traditional singing techniques as well to get contrasting sections to the abstract sound textures conducted by The Max Maestro. The idea was to explore a wide range of aspects using the human voice and electronic processed sounds of the human voice as musical expressions. The three interactive Singing Instruments!! were also included in the performance.

The composition was finally structured in eight movements dealing with different aspects of the human voice and electronically processed sounds of the human voice as musical instruments. The rehearsals were performed in groups, since it was impossible to gather all the hundreds of participants before the concert. Approximately two hours of rehearsal was made with each group. The grand rehearsal took place the same day as the concert and was the first time when all participants performed the composition together.

Step 2: Action. The premiere of Voices of Umeå Part III: Everybody Scream!!! was performed at Norrlandsoperan, Umeå by approximately two hundred non-professional singers, the Singing Instruments!! and electronic preprocessed sounds of voices through a multichannel speaker system. The two hundred non-professional singers were divided in eight individual parts. The composition had a total duration of 45 minutes and was conducted by the Max Maestro - an animated music notation system and Tomas Pleje. ${ }^{15}$

Step 3: Analysis of Results. The audio recording of the performance was used as the main data to be analyzed. From an artistic point of view, the performance was satisfying. Even if the scheduled three hundred and fifty participants had gone down to approximately two hundred participants, due to unexpected cancellations the artistic expression was unique. The crowd was able to perform polytempo textures, static and moving approximate pitch cluster textures, noise formation textures and rhythmical accents and text canons as intended. Especially the texture-based musical material was interesting to hear. The Max Maestro was shown to successfully conduct the two hundred participants divided in eight individual parts. Since the animated notation was showing approximate performance instructions in terms of pitch and dynamics the actual sounds generated by each individual performer was unique and with all combined together contributing to an advanced musical texture. According to my own reflections one of the key factors of why the intentions with the Max Maestro were shown to be successful was related to the choice of instrument. Using the human voice instead of a physical instrument made it possible for the performers to have their full attention to the visual output of the Max Maestro instead of the need to visually concentrate on a physical instruments. (Lind, 2015) 


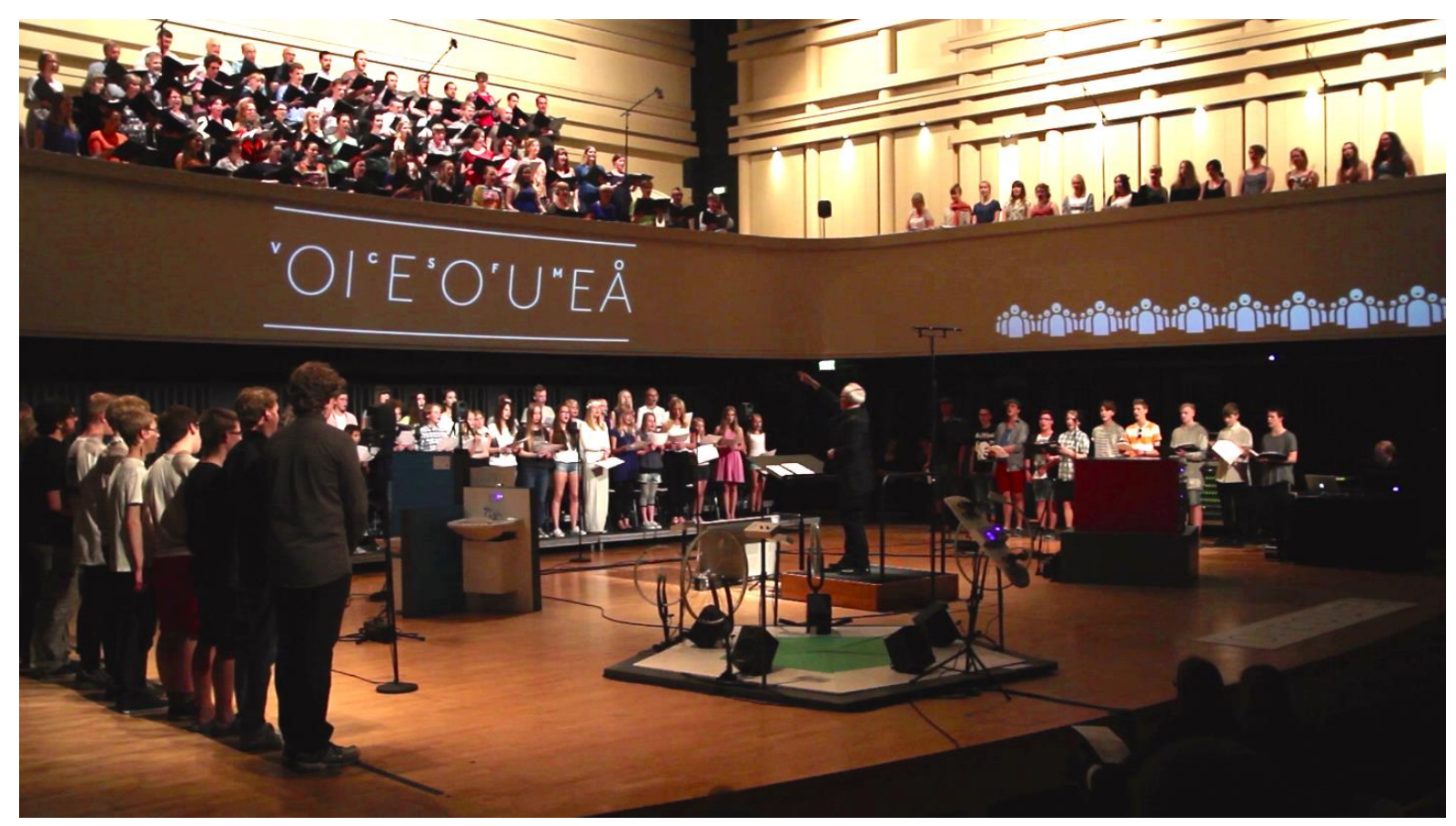

Everybody Scream!!! live Norrlandsoperan 2014.

\section{Reflections and future plans}

This article has described selected parts of the process and the findings of the Voices of Umeå project. The findings reported have shown a process, which evolved in cycles inspired by an action research method to seek new answers to the fields of animated music notation and participatory art. More specifically, - How to enable non-professional performers to participate in advanced composition and performance practices to enhance an artistic expression?. The project was conducted with an interdisciplinary approach guided by an artistic and pedagogical perspective, which sought to contribute to innovatory solutions of the defined research questions.

\section{Artistic research}

I started this project with some questions about the differences between artistic research and artistic practice. For me they still have a lot in common, but the main difference I would say is the aim of artistic research to develop new knowledge back to the field of artistic practice and/or artistic research. Furthermore, the documentation part is important in an artistic research project, which not necessary would be the case in a straight artistic project. Obviously, the documentation has to be there to strengthen the credibility of the new knowledge explored and presented within an artistic research project. However, it's hard to say to what extent the documentation should be made and how it should be presented, since it has to be dependent on the aim and process of the particular project. In terms of the Voices of Umeå project the new knowledge to be explored and presented back to the field was how non-professional performers regardless musical background could participate in contemporary art music processes to enhance the artistic expression. For me the three artistic compositions were a significant part of the project, both as stand alone artistic explorations and as a vital part of the methodology in the research process to answer the defined 
knowledge gap. The artistic compositions needed to be put into action to search for new answers, and in the contrary: The answers would affect the further composition process within the project.

The open process of the project with some formulated aims to start from evolving in multiple cycles and affected by the interdisciplinary approach, lead in many different directions with interesting analysis of results during the project. From a negative perspective the project could be accused of lacking focus, due to this huge amount of data, experiences and impressions the project have generated. Still, I believe this open process was one of the most interesting parts of the project. If I had considered narrowing the aims and the framework of the project, I am not sure if that as a consequence had given me as much interesting results. The Max Maestro - an animated music notation system was definitely a result of the open process, the methodology chosen and the interdisciplinary approach of the project.

\section{Artistic perspective}

From the artistic perspective the point of departure for this project was: -what would happen to the artistic result if non-professional performers regardless musical background would be able to participate in a composition written within the field of contemporary art music?. As a composer it was rewarding to work with voices of non-professional performers in this project. (1), to work with the voices recorded by the two voice recording instruments in the composition process, and (2), to work with the crowd of voices in the live performances of the compositions. The voice recording instruments were shown to inspire the citizens of Umeå to make expressive, naïve and unique sounds with their voices, which definitely would have had another expression if made by professional singers. Furthermore, the citizens had in this voice collecting process a deep impact on the artistic expression for the project, which were an interesting approach to participatory art and a challenge for me as a composer. Since the fundamental sounds were created intuitively by the citizens and not as a result of me as a composer instructing a performer, the composition process were guided by the actual expressions of the recorded sounds. As a composer I needed to have my full attention to the created sounds and to let them guide the composition process, instead of focusing on creating advanced performance notation instructions to a professional musician. This approach really inspired me as a composer.

Working with non-professional performers using their voices in a performance situation has in my previous works been complicated. The main issue has been to get the performers organized as wanted for an artistic expression without the use of traditional notation or a traditional conductor. Another issue has been to engage the performers using their voices in an expressive way, since our voice is very personal and it could be seen as uncomfortable using it in an unusual way in public. The use of the Max Maestro - an animated music notation system has in this project shown to overcome these issues. One factor could have been the use of a system more inspired by videogames than traditional music notation. The Max Maestro has shown to both give performance instructions for eight individual parts and to engage the performers to make expressive sounds with their voices. Furthermore, I found the artistic expression as a result of having a crowd of non-professional performers using their voices conducted by the Max Maestro as rich and unique. Especially the polytempo- and 
various noise- and cluster textures were shown to suit the approach perfectly. As an example the screaming cluster textures could be mentioned, which I doubt that professional singers had accomplished with such expressiveness. Also moving cluster textures accomplished by various glissandi movements and polytempo textures using various individual sounds on vowels in different pitches are examples of interesting artistic expressions.

The results of integrating the Max Maestro as performance instructor/ conductor in this project, opens up new exciting artistic possibilities within the concept of participatory art. With the use of the Max Maestro a large crowd of non-professional performers could perform a large-scale compositions involving advanced musical textures and electronics. The system has also shown to enable conducting performances of long duration compositions with very limited rehearsal time needed for the performers, which removes a lot of practical issues for these large-scale performances. As a result of this project the ambition is now to further develop the Max Maestro to enable new artistic explorations. In this project the human voice was in focus as performing instrument, but possibilities of having optional instruments could also be explored. How would it sound if the crowd was set to perform percussion instruments conducted by the Max Maestro? or specially designed Laptop instruments/ Computer tablets as instruments triggering electronic sounds?. Furthermore, unique orchestra settings combining a professional chamber/symphony orchestra with a crowd of for instance, school children or the audience could be created to explore new artistic expressions. As previously said, having a crowd of non-professionals, as performers have been artistically stimulating in this project. The artistic expressions created within the project could be described as both unique and complex. However, using high-skilled professional performers with all their knowledge, backgrounds and skills is still invaluable for an artistic exploration of new artistic expressions. Nevertheless, I argue that the expression created by a crowd of non-professional performers could serve as a fascinating artistic complement to the expressions of a professional orchestra. Combining the unique artistic qualities of the both two worlds into one musical body could be a new and interesting approach to seek for new musical expressions.

From an artistic perspective it was also rewarding working with the interactive instruments in the Singing Instruments!! exhibition created as the second composition within the project. By connecting the everyday objects to musical parameters, as a composer I could in real-time test my musical ideas by physically interacting and moving the everyday objects. As an example it was inspiring to physically test ideas for polytempo textures by spinning the wheels of the Wheel Quintet in different tempos. Furthermore, the Drawer Septet was an intuitive tool for me to test various ideas for cluster textures, opening and closing different combinations of drawers at various speeds. The exhibition made it possible for me to work with novel interactive instruments as an artistic tool and having the unique behaviors of the instruments to affect my artistic process for a composition. Furthermore, it was fascinating to connect the electronically processed sounds to a physical body, with an aim to visualize the sounds. Thus the instruments became physical bodies for the electronic sounds instead of a pair of speakers in the concert situation. Working with the Singing Instruments!! have given me lots of ideas to develop new interactive instruments, which should stimulate the creation of new artistic outputs. The Singing Instruments!! is a good example within the project where the pedagogical perspective was important for the artistic outcome. 


\section{Pedagogical perspective}

Having a pedagogical perspective to influence the artistic processes was rewarding for the final artistic expressions within the project. In the contrary, having the artistic processes to influence the pedagogical perspective led to the development of the Max Maestro and the three interactive instruments in the Singing Instruments!! exhibition within the project. These novel technology innovations both have artistic and pedagogical advantages. Since both The Max Maestro and the three interactive instruments were shown to enable non-professional performers including schoolchildren to perform advanced musical structures, they are interesting from a pedagogical perspective. With the use of the Max Maestro as a pedagogical tool the non-professionals could perform musical textures as polytempo textures, static and moving approximate pitch cluster textures, noise formation textures, rhythmical text canon and rhythmical accents. Consequently, these results gives me new ideas including putting the Max Maestro in the classroom, having school children to learn about music and musical structures by performing advanced musical textures within the genre of contemporary art music. Since the schoolchildren participating in the Voices of Umeå project managed to perform advanced musical textures with limited rehearsal time, the Max Maestro has shown to be an intuitive pedagogical tool, which probably could be used in an educational environment. However, more research has to be done within the domain of having animated music notation in an educational environment to point out any definite results.

The interactive instruments for the Singing Instruments!! exhibition were also summarized as interesting novel pedagogical tools to enable schoolchildren performing advanced musical structures. The results from the workshop sessions with the children were interesting and the instruments were shown to be intuitive, playful and inspiring. My experiences participating in these workshop sessions indicate that these types of new technology innovations as new musical instruments and pedagogical tools could be a complement to the traditional acoustical instruments we use in our educational environment. It was exciting to test the pedagogical ideas with the school children, but of course new more practical instruments needs to be developed if they should have the purpose of being part of a school environment.

\section{Coda}

As a final conclusion the participatory aspect of the project was shown to be satisfactory. More than ten thousand sound files were collected from the citizens of Umeå and the performances included hundreds of performers, which normally don't participate in these types of experimental musical processes. The large amount of participators in the project was according to my own reflections dependent on a variety of different aspects: Collaboration with several music institutions, organizations and others outside the sphere of the university, an interesting and engaging artistic idea, lots of exposure in various media ${ }^{16}$, the use of playful interactive instruments and the project was being a part of the Umeå municipality's European Capital of Culture program in 2014.

In addition to the actions and activities mentioned in this article different parts of Voices of Umeå have been presented, exhibited and performed internationally in venues/ universities/

16 The project included a strategy to get media writing about events within the project to reach out to potential new participators. 
conferences such as: CHI'13/Paris ${ }^{17}$, Ircam Institute/Paris ${ }^{18}$, Felleshus/Berlin ${ }^{19}$, UCSB/Santa Barbara/California $^{20}$, Waterloo Innovation Summit/Waterloo/Canada ${ }^{21}$, CNMAT/Berkeley/ California $^{22}$, Center for New Music/San Francisco ${ }^{23}$ and NIME 2016/Brisbane/Australia ${ }^{24}$.

The results reported in this artistic research project contributes with new knowledge on how to enable non-professional performers to participate in composition and performance practices to enhance an artistic expression within contemporary art music. I encourage new research especially in the domains of animated music notation and participatory art to further explore these approaches seeking for new artistic possibilities.

\section{References}

\section{Articles/Papers/Projects}

Arlander, Anette (2014), "On methods of artistic research", in Torbjörn Lind/ Swedish research council (ed.), Method process reporting, Artistic yearbook 2014. Stockholm: Swedish Research Council. Pp. 27-39.

Freeman, Jason (2008), "Glimmer: Creating new connections", in Randy Adams, Steve Gibson, Stefan Muller Arisona, Transdisciplinary Digital Art. Sound, Vision and the New Screen. Berlin Heidelberg: Springer. Pp. 270-83.

Freeman, Jason, and Mark Godfrey (2010), "Creative collaboration between audiences and musicians", in Flock, Digital Creativity, 21,2: 85-99.

Fällman, Daniel (2003), "Design-oriented human-computer interaction." Proceedings of the SIGCHI conference on Human factors in computing systems. ACM, 2003.

Fällman, Daniel (2008), "The interaction design research triangle of design practice, design studies, and design exploration", Design Issues 24,3: 4-18.

Hannula, M, J. Suoranta, T. Vadén, G. Griffiths, and K. Kölhi (2005), Artistic research: Theories, methods and practices. Helsinki, Finland: Academy of Fine Arts, and Gothenburg, Sweden: University of Gothenburg / ArtMonitor.

Hope, Cat, and Lindsay Vickery (2011), "Screen scores: New media music manuscripts", in Proceedings of the International Computer Music Conference 2011. Centre for Research in New Music, University of Huddersfield, United Kingdom.

Kelly, Michael (2014), "Participatory art", in Michael Kelly (ed. in chief), Encyclopedia of Aestetics. Oxford: Oxford University Press.

Lewin, Kurt (1958), Group decision and social change. New York: Holt, Rinehart and Winston.

Lind, Anders (2015), Voices of Umeå: an artistic research project, (Department of Creative studies/ Umeå university/ Sweden, 2013-2015) http://www.estet.umu.se/konstnarligforskning/anders-lind/_visited 14 December 2015.

17 Human Computer Interaction <http://chi2013.acm.org>

18 Institut de Recherche et Coordination Acoustique/Musique <http://www.ircam.fr>

19 Felleshus is a public space for cultural events at the Nordic embassies, run by the five Nordic countries.

$<$ http://www.nordicembassies.org>

20 University of California/ Santa Barbara

$21 \mathrm{https}$ //waterlooinnovationsummit.com

22 Center for New Music and Technology. 〈http://cnmat.berkeley.edu>

23 <http://centerfornewmusic.com>

24 New Interfaces for Musical Expression <http://nime2016.org> 
Lind, Anders (2015), "New Artistic Possibilities with The Max Maestro - An Animated Music Notation System for Non-Professional Performers." http://www.researchcatalogue.net/view/224363/224364 visited 14 December 2015.

Lind, Anders, and Daniel Nylén (2016), "Mapping everyday objects to digital materiality in The Wheel Quintet: Polytempic music and participatory art", in Proceedings of NIME conference, Brisbane, Australia 2016.

Mc Kenna, Shane (n.y.), "Animated graphic notation", paper at ISEA2011 Istanbul (International Symposium on Electronic Art).

Myllykoski, Mikko, Kai Tuuri, Esa Viirret, and Jukka Louhivuori (2015), "Prototyping handbased wearable music education technology", in Proceedings of NIME conference, Baton Rouge, LA, USA.

Novitz, David (2001), "Participatory art and appreciative practice", The Journal of Aesthetics and Art Criticism 59.2: 153-65.

Ravini, Sinziana (2013), "Artistic research in social and knowledge terms", in Torbjörn Lind (ed.), Artistic research then and now: 2004-13, Yearbook of AR\&D 2013. Stockholm: Swedish Research Council. Pp. 107-28.

Rolo, R. (2011), "Singstar - Applying to music education”, in T. Bastiaens \& M. Ebner (eds), Proceedings of EdMedia: World conference on educational media and technology 2011. Association for the Advancement of Computing in Education (AACE). Pp. 31923201.

True, Nicholas, Nigel Papworth, Ru Zarin, Jeroen Peeters, Fredrik Nilbrink, Kent Lindbergh, Daniel Fällman, and Anders Lind (2013), "The voice harvester: An interactive installation", Proceedings of the CHI '13 conference: Extended Abstracts on Human Factors in Computing Systems, 3003-06.

Vickery, Lindsay, and Cat Hope (2010), "The aesthetics of the screen score. Proceedings of CreateWorld. Brisbane, Australia. Pp. 48-57.

Weitzner, Nathan, Jason Freeman, Chen Yan-Ling and Stephen (2013), "massMobile: towards a flexible framework for large-scale participatory collaborations in live performances", Organised Sound, 18: 30-42.

Wyatt, A. K, and C. Hope (2013), "Animated music notation on the iPad (or: Music stands just weren't designed to support laptops)", in Proceedings of the 2013 ICMC Conference. Pp. 201-7.

\section{Music Compositions/ Video games/ Applications}

Cage, John. 1991. 108. https://www.youtube.com/watch?v=3H5WfJJ7LVs visited 18 October 2016

Guitar Hero. 2005. https://www.guitarhero.com visited 14 December 2015

Hope, Cat/ Vickery, Lindsay. 2011. Decibel Score Player. https://itunes.apple.com/us/app/decibel-scoreplayer/id622591851?mt=8 visited 14 December 2015

Lind, Anders. 2014. The Max Maestro: an animated music notation system. https://www.youtube.com/watch?v=4iePLi5uQzU visited 14 December 2015

Lind, Anders. 2008. Röster från Umeå https://www.youtube.com/watch?v=XdLngKj7Zno visited 14 December 2015

Lind, Anders. 2013. Voices of Umeå part I: We Speak Music!. https://www.youtube.com/watch?v=hl1aGHXHOME visited 14 December 2015

Lind, Anders. 2014. Voices of Umeå part III: Everybody Scream!!!. https://www.youtube.com/watch?v=VFebLXpe0fo > visited 14 December 2015

Lind, Anders. 2013. Voices of Umeå part II: Singing Instruments!!. https://www.youtube.com/watch?v=wLQ5Hs4GTeU visited 14 December 2015 
Lind, Anders. 2009. Music for Chamber Ensemble and Five Electronic Conductors. https://www.youtube.com/watch? $\mathrm{v}=\mathrm{e}$ _197ND1kvE visited 14 December 2015

Lind, Anders. 2009. Myggan. https://www.youtube.com/watch?v=Vfk37Te9n0g visited 14 December 2015

Lind, Anders. 2011. Voltage Controlled Orchestra. https://www.youtube.com/watch?v=CX7dhWag3Z4 visited 14 December 2015

Lutoslawski, Witold. 1964. String Quartet. https://www.youtube.com/watch?v=y6NjoYzqDbg visited 14 December 2015

Mc Kenna, Shane/ Redmond, Killian. 2012. Dabbledoomusic - Animated notation application for children. http://www.dabbledoomusic.com visited 14 December 2015

Pálsson, Páll Ivan. 2012. Eiðahólmi. https://www.youtube.com/watch?v=MJbs4ushyEc visited 14 December 2015

Penderecki, Krzysztof. 1960. Threnody for the Victims of Hiroshima. https://www.youtube.com/watch?v=HilGthRhwP8 visited 14 December 2015

Sing Star. 2004. https://www.singstar.com/sv/about.html visited 14 December 2015

Smith, Ryan Ross. http://animatednotation.com visited 14 December 2015

Smith, Ryan Ross. 2012. Study no. 8 [15 Percussionists] [2012]: for 15 percussionists. https://www.youtube.com/watch?v=bhhCu_QA3e4 visited 14 December 2015 